\title{
2013-2018: CINCO AÑOS DE INTERVENCIÓN EN EL PATRIMONIO ARQUITECTÓNICO DE MARRUECOS
}

\author{
Ubaldo García Torrente. \\ Doctor en Arquitectura. Profesor Área de Proyectos Arquitectónicos. \\ Escuela Técnica Superior de Arquitectura. Universidad de Granada. \\ ubaldo@garciatorrente.com
}

Marisol García Torrente. Doctora en Arquitectura. Máster en Arquitectura y Patrimonio Histórico. Profesora Área de Proyectos Arquitectónicos. Escuela Técnica Superior de Arquitectura. Universidad de Granada.marisol@garciatorrente.com

Resumen: En noviembre de 2018, los autores del artículo cumplirán veinte años de vinculación con la Universidad de Granada. Desde el principio, como profesores de la asignatura de Proyectos en la Escuela de Arquitectura, planteamos la necesidad de hacer un registro científico-proyectual de la arquitectura y los paisajes que construyen las diversas culturas de Marruecos. El programa genérico denominado Latitudes, sirve para posicionar al estudiante en el reconocimiento de lo diverso que emana del reconocimiento de las prácticas culturales ligadas al territorio ocupado por los grupos humanos que lo habitan y que en el país vecino se manifiesta de manera evidente. Lo que a continuación se presenta es una síntesis de algunos de esos trabajos realizados entre 2013 y 2018. Una sintesis que muestra de las diferentes vías e intereses perseguidos en las distintas situaciones abordadas. Trabajos cuyo valor reside en la reflexión atenta y desprejuiciada de lo que significa la intervención contemporánea sobre el patrimonio y la obligación de protegerlo, conservarlo y ponerlo en valor.

Palabras Clave: Arquitectura, Proyectos, Rehabilitación, Patrimonio, Paisaje, Territorio, Marruecos.

Abstract: In november 2018, the authors of the article will celebrate twenty years of collaboration with the University of Granada. From the beginning, as professors of Projects course in the School of Architecture, we raised the need to make a scientific-design record of the architecture and landscapes which build the diverse cultures of Morocco. The generic program called Latitudes, serves to face the students with the recognition of the diversity that comes from the recognition of cultural practices linked to the territory occupied by its inhabitants, which is obvious in this neighboring country. What follows is a synthesis of some of those works carried out between 2013 and 2018. A synthesis that shows the different ways and interests pursued in the different situations addressed. Works whose value lies in the careful and unprejudiced reflection of what contemporary intervention on heritage means and the obligation to protect it, preserve it and value it. 
Keywords: Architecture, Projects, Rehabilitation, Heritage, Landscape, Territory, Morocco

\section{Introducción}

Los primeros viajes realizados en los años de juventud a Marruecos nos dieron una perspectiva nueva de la arquitectura, algo que comenzamos a valorar con el paso del tiempo y en tantos otros viajes que les sucedieron. Vislumbrábamos en esos paisajes que percibíamos, tan lejanos y tan cercanos a la vez, algo diferente. Algo que, sin saber por qué, se iban haciendo necesario en nuestras vidas personales y, desde luego, en el ámbito profesional. Es difícil precisar cuándo se generó ese vínculo, pero parece claro que, al menos en aquella época, Marruecos aún preservaba dinámicas culturales territoriales propias muy alejadas de las dinámicas globales contemporáneas en las que ya estábamos inmersos en Europa, portadoras de conocimientos prácticos en todos los ámbitos del saber, muy vinculados a la tierra y a la especificidad del ámbito geográfico y humano propiamente vivido. Cuando a finales del siglo pasado comenzó nuestra labor de profesores de proyectos en la Escuela de Arquitectura de Granada, planteamos la necesidad de registrar la rica arquitectura y los paisajes que construyen las diversas culturas de Marruecos. La diversidad paisajística de este país del que apenas nos separan unos kilómetros y con el que compartimos fuertes lazos culturales que han sido recurrentes a lo largo de siglos, nos condujo a considerar que Marruecos debía ser una constante en nuestros planteamientos proyectuales docentes, de ahí que, al menos una vez al año, los ejercicios del taller de proyectos 6 y 7 dedicados respectivamente a la intervención en el patrimonio y al paisaje cultural, se emplazara en algún lugar de Marruecos en el que todavía fuese posible asistir y comprender la magia de lo que ocurre cuando naturaleza y humanidad transitan por caminos convergentes

El programa genérico denominado Latitudes, se planteó, y aún sigue vigente, con la intención de posicionar al estudiante en el reconocimiento de lo diverso y diferenciado que emana, no de un proceso inventivo abstracto y descontextualizado, sino del reconocimiento de las prácticas culturales ligadas al territorio apropiado, ocupado y vivido por los grupos humanos que lo habitan. El proyecto de arquitectura se plantea, en consecuencia, a partir del registro de aquellos aspectos que en los distintos ámbitos se manifiestan de forma específica y diferenciada, proclives a la formalización de las diferentes formas de asentamiento y modelos de hábitats, en definitiva, de producción arquitectónica y paisajística, que surgen de las distintas formas específicas de relación entre 
los diferentes grupos humanos y los territorios donde habitan, formas de relación que en gran medida vienen mediadas por la cultura.

La cultura es importante porque, en palabras del antropólogo Edgard Morin (1991, p.19), puede describirse como "una máquina cognitiva cuya praxis es cognitiva". En síntesis, como una especie de megaordenador que guarda y gestiona el saber colectivo acumulado, la memoria social de un pueblo, expresándose en forma de modelos, esquemas de conocimiento, visiones del mundo, cosmologías diversas, formas lingüísticas, mitos o ritos. Desde esta perspectiva cultural, el territorio, objeto de estudio y transformación de la arquitectura es espacio antropizado, elegido, seleccionado y transformado para vivir, que sin el hombre social inmerso en un determinado contexto cultural, carece de sentido. Es "el espacio apropiado y valorizado simbólica e instrumentalmente por los distintos grupos humanos" (Raffestin, 1980, p.129), (Giménez, 2000, p.20).

Cada cultura enfatiza de forma diferenciada los aspectos utilitarios del territorio, por ejemplo en términos de explotación económica o de ventajas geopolíticas. También el papel del territorio como espacio de sedimentación simbólico-cultural, como objeto de inversiones estético-afectivas o como soporte de identidades individuales y colectivas. Que el territorio sea objeto de operaciones funcionales y a la vez simbólicas, quiere decir que funciona como una especie de pantalla sobre la que los diferentes actores sociales: individuos y colectivos, proyectan sus concepciones del mundo, sus propias cosmologías. Esto hace, en palabras de Gilberto Giménez, que el territorio pueda ser concebido desde múltiples dimensiones interrelacionadas, cómo "zona de refugio, como medio de subsistencia, como fuente de recursos, como área geopolíticamente estratégica, como circunscripción político-administrativa..., también como paisaje, como belleza natural, como entorno ecológico privilegiado, como objeto de apego afectivo, como tierra natal, como lugar de inscripción de un pasado histórico y de una memoria colectiva, incluso como geosímbolo ${ }^{1}$ (Giménez, 2000, p. 21-22).

Los diferentes grupos humanos caracterizan los espacios geográficos donde habitan, transformándolos de forma funcional y simbólica, según una específica cultura del territorio que constituye el más elemental y a la vez complejo y elaborado patrimonio de una sociedad. Elementalidad con la que se elaboran el conjunto de respuestas primarias de cualquier comunidad humana a las limitaciones, dificultades y recursos que encuentra en su propio espacio vital. Complejidad y elaboración que emanan de la acumulación de experiencias fallidas y exitosas que han ido conduciendo a los productos más elaborados, de dicha cultura territorial 
que son los paisajes (Ojeda, 2006, p.87).

“... Salvo en las regiones boreales más extremas, la Antártida y algunas zonas ecuatoriales, los paisajes naturales no son otra cosa que los éxitos de esa relación, los resultados de la lenta y armoniosa interacción de las poblaciones humanas con su entorno, al que llamamos naturaleza" (Parra, 2006, p.4)

Los paisajes culturales son aquellos espacios que se han ido conformando a lo largo de un prolongado proceso histórico de antropización, resultado del continuo tránsito y asentamiento de los diferentes pueblos y culturas que lo han habitado y explotado. Como consecuencia de ello, las huellas materiales e inmateriales, más o menos alteradas, que sus pasos han dejado en esos territorios, constituyen los instrumentos que hacen posible percibir y concretar los valores y bienes culturales que están presentes y se conservan en ellos y que es necesario proteger. Bienes culturales de gran valor patrimonial que han sido, en definitiva, objeto de nuestra consideración e investigación a lo largo de estos años.

Es importante para la reflexión de la arquitectura que se enfrenta a la intervención en el patrimonio, no pensar en la cultura del territorio, ni en los paisajes culturales y bienes patrimoniales que produce, como un proceso estable. Al igual que cualquier otra manifestación, la cultura del territorio está vinculada a lo vivencial y adaptativo. Está marcada irremediablemente por la temporalidad, inexorablemente sujeta a los cambios y transformaciones azarosos de la vida. Este constante proceso de cambio y transformación obliga a un continuo estado resiliente de adaptación a las nuevas exigencias, demandando una continuada dinámica de apropiación y permanentemente reactivación por sujetos dotados de capital cultural incorporado, es decir, del habitus requerido para releerla, interpretarla y valorizarla en su justa medida, pues de lo contrario se olvida y se extingue (Giménez 2007, p.97). Más allá del objeto, aunque también, nos interesan esas dinámicas que permiten cambios y transformaciones que ayudan a progresar de forma sostenible con el bien, conscientes de que los problemas surgen cuando la realidad objetiva cambia y la cultura no consigue reactivarse volviéndose disfuncional para atender a las nue-

El Geosímbolo es un marcador espacial, un signo en el territorio que focaliza a la vez que construye identidad. Puede ser un lugar santo, venerado o sagrado como una montaña, bosques, ríos, manantiales, cuevas.... Estos lugares o sitios expresan, en efecto, un sistema de valores comunes que pueden dar origen a peregrinaciones (Bonnemaison, 1981, p. 55) 
vas circunstancias. El necesario cambio cultural, entonces, se produce como desplazamiento de significados, haciendo imposible su reciclaje y reactivación. De aquí su condición efímera y frágil.

"Es el proceso social y no el objeto lo que se debe preservar para garantizar la creatividad continuada de una comunidad" " Por encima de todo, el deseo de preservación debe estar encaminado a hacer posible que quienes son depositarios de culturas tradicionales continúen ofreciendo modelos alternativos" (Prott, 2001, p. 156-157))

En la actualidad nos enfrentamos a procesos de aculturación generalizados que inciden significativamente en las dinámicas territoriales contemporáneas. La subyugación de la diversidad cultural a una única cultura global que homogeniza y geometriza territorios rurales o marítimos que hasta hace escasamente ocheta años existían, es más que manifiesta, por lo que en muchos lugares del planeta, es cada vez más complejo que puedan subsistir lugares o territorios culturales que resistan el empuje de la globalización y las dinámicas territoriales que ésta impone. Conscientes de ello, creemos necesario y así lo hemos potenciado a lo largo de estos años, aportar propuestas y alternativas arquitectónicas que vayan encaminadas fundamentalmente a posicionar a la cultura del territorio, sus conocimientos compartidos y prácticas diversas en el territorio y la arquitectura, en el escalafón que le corresponde por haber demostrado durante siglos ser la opción más sostenible, respetuosa y resiliente medioambientalmente hablando. El programa Latitudes surgió, precisamente, para dar respuesta a estas inquietudes, para fomentar el uso de una investigación participativa que surgiera de la unión entre ciencia, experiencia de la vida, conocimiento y sabiduría, que no esté huérfana del factor humano, de manera que ésta ayude a transcribir, para que no se pierdan, todas esos conocimientos y saberes vinculados a las formas de transformación del territorio y los hábitats que construyen, testimonios todavía vivos de una particular cultura del territorio. También, y esto es fundamental, para que puedan estar a disposición de forma útil y contributiva a los profesionales que ejercen su actividad profesional en el patrimonio.

Lo que a continuación se presenta es una síntesis de algunos de los trabajos de curso que bajo los epígrafes de "Estrategias Urbanas", "Paisaje Urbano", "Arquitectura y Grandes infraestructuras", "Renovación habitacional y Urbana", "Paisaje en Ruina", "Patrimonio Inmaterial" y "Agua y Poder", se han realizado durante los últimos 5 años, entre 2013 y 2018, en el Taller de Proyectos Arquitectónicos que dirigimos. Una síntesis de los cuarenta trabajos que de promedio se entregan por cada ejercicio 
semestral, más de mil quinientos en total, que en su esencia sirven como enunciado y muestra de las diferentes vías e intereses perseguidos en las distintas situaciones espaciales, constructivas y territoriales abordadas. Trabajos brillantes, sin duda, pero cuyo valor principal reside en cuanto suponen de reflexión atenta y desprejuiciada de lo que significa la intervención contemporánea en el patrimonio, un legado vivo recibido al que se debe proteger, conservar y valorar para el uso y disfrute de las futuras

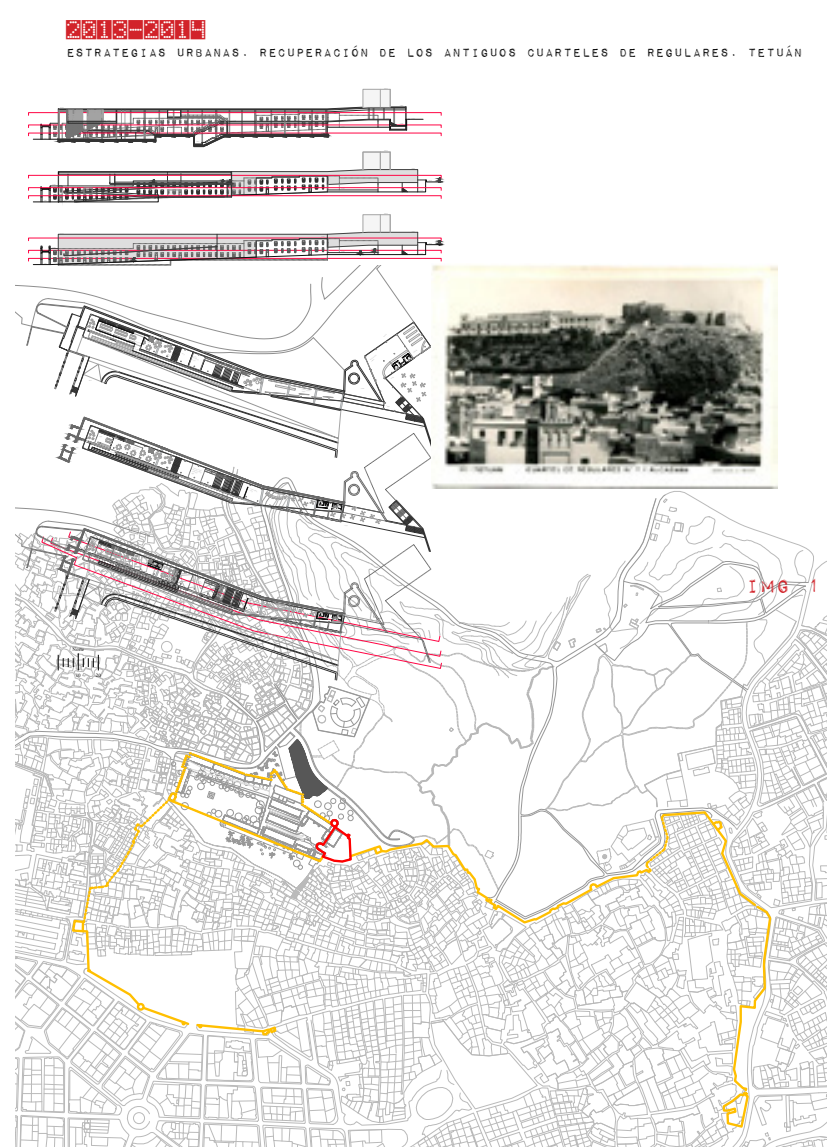

Fig. 1. 2013-2014. Taller de Proyectos 6. ETSA Granada. ESTRATEGIAS URBANAS. Recuperación de los antiguos cuarteles de Regulares. Tetuán.

Elaboración propia a partir de: Levantamiento colectivo sobre base cartográfica. Nov. 2013. Ana Isabel Rodríguez Aguilera. Propuesta de intervención en el Cuartel de Regulares de la Alcazaba. Nov. 2013. Carta postal. Calatayud. Tetuán. Cuartel de Regulares $n^{\circ} 1$ y Alcazaba. Recurso web: Todocolección. https://www. todocoleccion.net/postales-ex-colonias-protectorado/postal-tetuan-original-sin-circular-anos-60-buen-estado-original-marruecos-es-foto $\times 47858286$ generaciones para que éstas puedan asimilarlo, usarlo y disfrutarlo como materia viva, de modo acorde a las circunstancias y al tiempo que les tocó vivir. [1]

Durante el Protectorado Español, la ciudad de Tetuán llegó asumir como propias, al menos cuatro realidades sociales y urbanas diferentes, un hecho que, a pesar de las similitudes con otras poblaciones cercanas, le conferiría un estado de excepcionalidad que la marcaría de manera sustancial: la de la población de origen musulmán que tradicional e históricamente había ocupado los diferentes barrios de la Medina, la de los judíos, prácticamente confinados desde principios del siglo XIX en El Mellah, la población civil, formada mayoritariamente por familias de inmigrantes españoles llegados desde la península que ocup- 
aban tanto el Ensanche como la Ciudad Jardín, así como los distintos barrios obreros que se construyeron en áreas periféricas y la de los militares y sus familias que habitaban en el entorno de los cuarteles y residencias propias. Situaciones urbanas que fueron cinceladas a partir de precisas reglas de conformación espacial y urbanística y que el microcosmos social tetuaní lograría redefinir, difuminando unos límites sociales y urbanos que en otras ciudades permanecieron férreamente custodiados hasta bien pasado el periodo colonizador. La comunidad sefardí, gracias a la práctica abolición de la Dimma, pudo ir abandonando paulatinamente su restringido espacio vital, mientras que los españoles de toda procedencia y estatus social vivían y trabajaban en la Medina de manera natural, algo que en simétrica correspondencia ocurría con no pocos musulmanes que disponían de pisos o negocios en el ensanche y más tarde en el Paseo de las Palmeras -Avenue Mauritanie- lugar al que inmediatamente se trasladó una parte de la población más adinerada.

Sin embargo, probablemente por su misión fundamentalmente defensiva y su posición estratégica, los acuartelamientos e instalaciones militares, parapetados tras sus altas tapias o monumentales fachadas, parecían estar al margen de esta fina urdimbre social a pesar de que la mayoría estaban físicamente ubicados, como una manzana más, en el corazón mismo del recientemente planificado Ensanche. Esta circunstancia marcó de tal modo su presencia urbana que, aún hoy, desprovistos ya de sus funciones originales, no parecen haberla superado. Tras la suspensión definitiva en 1956 del Estatuto que regulaba las atribuciones del Protectorado Español y hasta 1961, se fue produciendo en todo el área y de forma escalonada, el sucesivo traspaso de competencias en los distintos ámbitos sociales y políticos y, como no, en el campo de la defensa. Disueltas la mayoría de las divisiones del ejército de Regulares y en paralelo a la cesión del gobierno de la ciudad a las nuevas corporaciones municipales, se hizo igualmente efectivo el traspaso de estos edificios al Ejército Real que no vio conveniente en aquel momento su continuidad funcional lo que provocó que, con el tiempo y en ausencia de un plan alternativo de reconversión, estos fueran deteriorándose físicamente e incrementando a pasos agigantados su autismo urbano.

La mayoría de estos edificios ya no existe. Algunos fueron derribados, como el Cuartel de Caballería, sustituido posteriormente por los $\mathrm{Pa}$ bellones Varela, residencia de ex militares y el actual Colegio Jacinto Benavente al oeste de la Medina, mientras que el solar que dejó el derribo del antiguo Cuartel de Artillería permaneció durante décadas abandonado y posteriormente usado como estacionamiento al aire libre, hasta que un 
dudoso proyecto de reciente construcción logró colmatarlo nuevamente. Sin embargo, a día de hoy, esta lógica destructiva aún no ha alcanzado a elementos tan importantes como el impresionante Cuartel de Regulares junto a la Alcazaba ni al de Jordana o R'Kaina, situado al sur del ensanche, los cuales, aunque en un avanzado estado de ruina y como si se tratara de fantasmas de un pasado incómodo, permanecen en pie quebrando las más elementales leyes de una deseable continuidad en la vida ciudadana.

Hasta ahora, ni el ejército, propietario de los inmuebles, ni las sucesivas corporaciones municipales, y mucho menos la ciudadanía, parecen
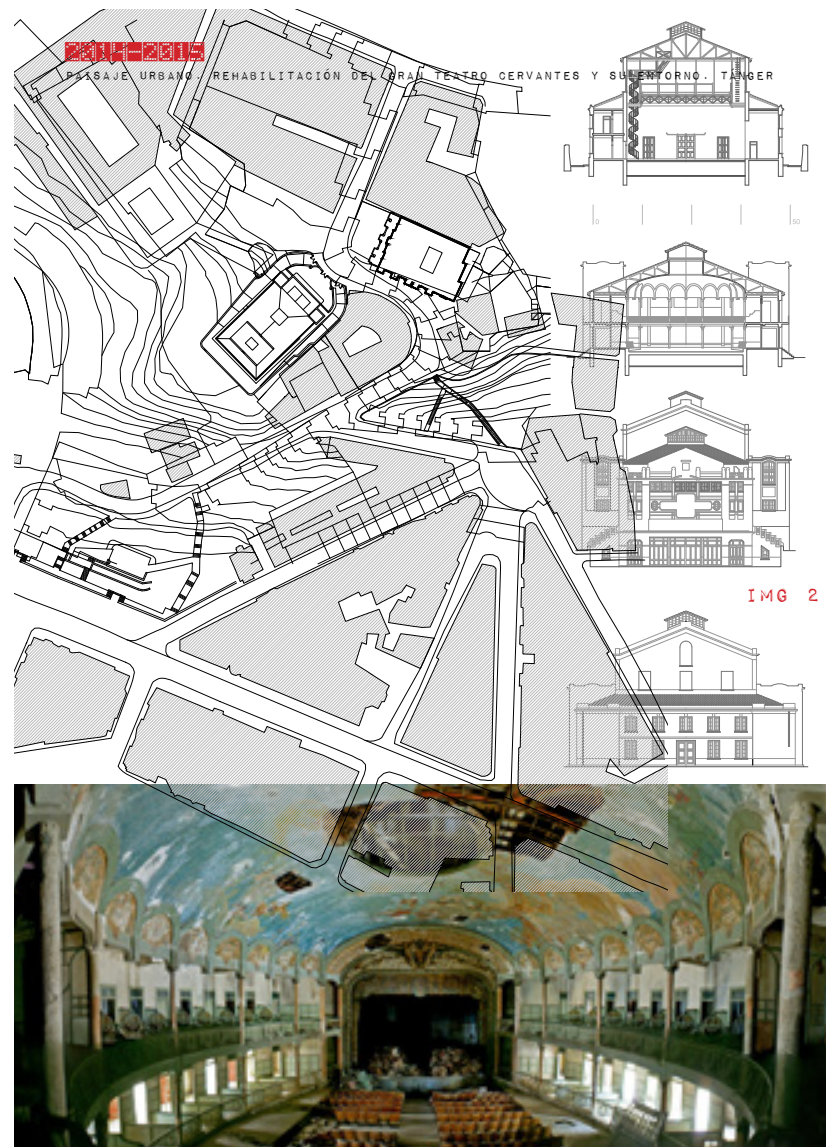

Fig. 2. 2014-2015 Taller de Proyectos 6. ETSA Granada. PAISAFE UR$B A N O$. Rehabilitación del Gran Teatro Cervantes y su entorno. Tánger. Elaboración propia a partir de: Planta general. Levantamiento colectivo sobre base cartográfica. Nov. 2014. Alzados y secciones: Levantamiento colectivo a partir de planos del proyecto de Rehabilitación del Gran Teatro Cervantes de Tánger. Velles Arquitectos. Nov. 2014. Fotografía: Sergio R. fiménez Montoya. Donde habita la memoria. asumir como propias estas piezas arquitectónicas de alto valor patrimonial impidiendo el digno rescate que merecen. El ejercicio propuesto en el curso 2013-2014 quiso poner el acento en estos elementos fundamentales para comprender la historia urbana de la ciudad, cuya importancia se sustenta aún hoy sobre la base de que son elementos fundamentales para definir y comprender el paisaje urbano tetuaní. Tras una necesaria y delicada puesta en valor de los bienes en cuestión, se elaboraron en el taller propuestas tendentes a su recuperación, realizando para ello los necesarios ajustes espaciales y constructivos, de manera que estos pudieran ser integrados definitivamente y de manera natural, en la vida social y urbana de una ciudad, atendiendo 
básicamente a sus aspiraciones colectivas. Una aproximación proyectual que no debe entenderse en ningún caso como una actitud conservadora en sí misma que implique cargar con el lastre de una experiencia social, política y urbana probablemente traumática, sino que pretendía partir de la consideración de que la memoria del transcurrir histórico, incorporada ahora a la construcción de la ciudad y el territorio, son aspectos que constituyen la personalidad de una determinada comunidad, los cuales, a su vez, contribuyen a su enriquecimiento y a ampliar las opciones de futuro de la población. [2 y 3]

Tánger, la ciudad blanca según la bautizó Pierre Loti, la azul de Paul Bowles, la gris de Truman Capote, no ha parado de reinventarse a sí misma desde que en el siglo XV fuera tomada por los portugueses. Lo único que parece no haber cambiado desde entonces es su condición de fronteriza, de su autoexclusión del entorno próximo. Tánger es una rareza, una esponja que lo absorbe todo y todo lo asimila de manera natural. Una ciudad en constante cambio, un prodigio de supervivencia y adaptación flexible, una ciudad de flujos y encuentros no duraderos, un centro cosmopolita en cualquiera de sus etapas históricas y urbanísticas. El 30 de marzo de 1912 se firma el Tratado del Protectorado Francés entre el gobierno de París y el sultán de Marruecos, el cual servirá de base para el que poco después, en abril de ese mismo año, se firmara con España,

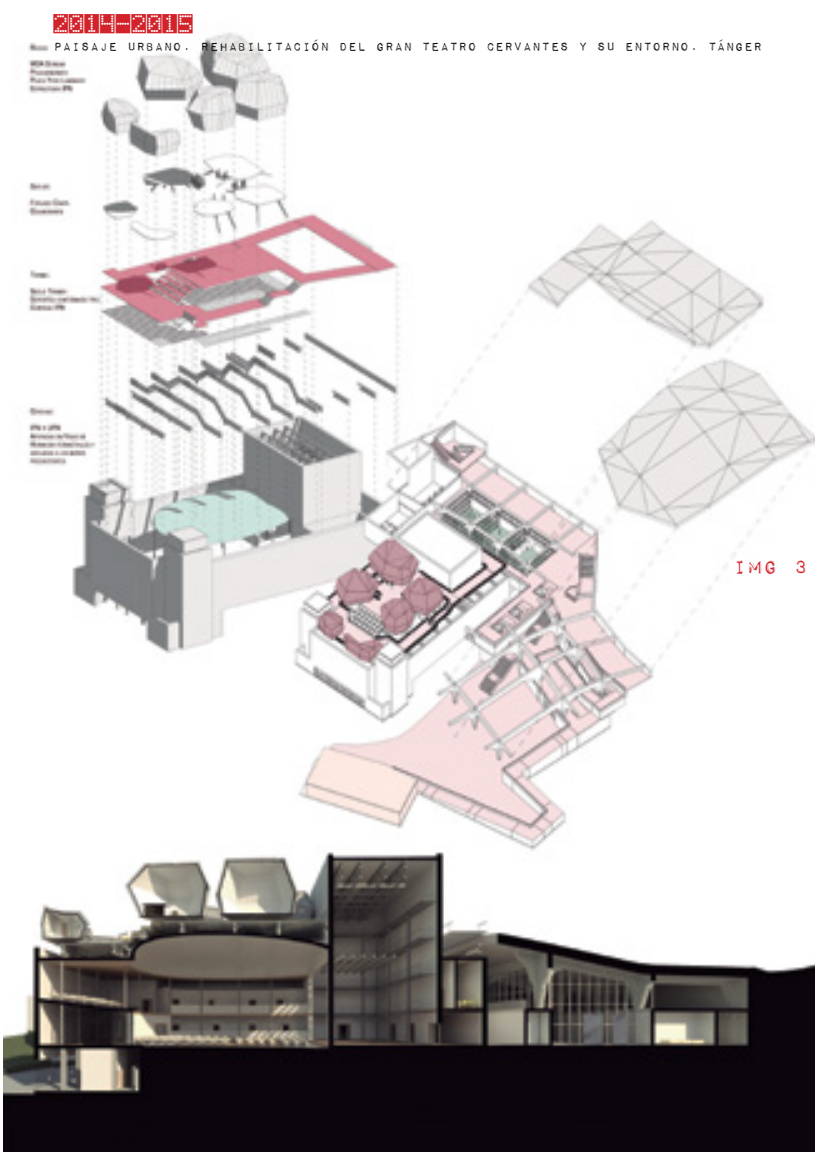

Fig.3. 2014-2015 Taller de Proyectos 6. ETSA Granada. PAISAFE URBANO. Rehabilitación del Gran Teatro Cervantes y su entorno. Tánger. Sergio R. Fiménez Montoya. Propuesta de intervención en el Gran Teatro Cervantes de Tánger. Feb. 2015. 
dividiendo el país en dos partes: al norte y al sur del Río Seb. La ciudad de Tánger, tras muchas negociaciones, quedaría fuera de ambas jurisdicciones ya que desde 1906 quedaría gobernada por un estatuto propio, el de Ciudad Internacional, según el cual quedaba reconocida como sede de todas las instituciones firmantes del acuerdo marco surgido de la Conferencia de Algeciras. A partir de ese momento la ciudad entra en una fase de reconversión con grandes inversiones por parte de cada una de las Legaciones, como una forma de reivindicación y afianzamiento: el puerto realizado tras la azarosa, corta y trascendental visita del Kaiser Guillermo de Alemania el 31 de marzo de 1905, las obras de saneamiento integral llevadas a cabo por la Comisión de Higiene y Limpieza de Tánger -que aunque había nacido en 1883 por iniciativa española, en esos momentos tendría una influencia definitiva en su desarrollo urbano-, cines, consulados, sedes de empresas de todo el mundo, etc. De la población extranjera, los españoles eran mayoría y estaba compuesta fundamentalmente por de emigrantes en busca de oportunidades, pero también de exiliados políticos e intelectuales ávidos de la libertad que en la ciudad ya empezaba a respirarse.

Una de aquellas obras se situó fuera de la medina y relativamente cercana a la playa, en una zona aún despoblada y desvinculada de la incipiente urbanización que con claves de modernidad arquitectónica iba modelando la Nouvelle Ville. "En la España de principios del siglo XX había matrimonios acaudalados, como el compuesto por Manuel Peña y Esperanza Orellana, que dedicaron parte de su fortuna a erigir un teatro y costear espectáculos deficitarios. Encargaron su construcción, en 1911, al arquitecto Diego Jiménez. Acaso cansados de asumir pérdidas traspasaron el Cervantes, 15 años después de su inauguración, en 1928, al Estado español." (Cembrero, 2013)

El Gran Teatro Cervantes de Tánger queda inaugurado en 1913 con una fiesta que no se olvidaría durante años, permaneciendo activo hasta casi la década de los sesenta cuando, casi hundido económicamente, cierra sus puertas tras la declaración de independencia de Marruecos. Más que un teatro, El Cervantes, nombre con el que se le conocía abreviada y popularmente, era una especie de centro cultural donde, además de los espectáculos ofrecidos por los más importantes artistas del momento y de las representaciones teatrales de todo calado o lengua, era posible celebrar cualquier tipo de manifestación social o cultural: mítines, conferencias, encuentros sociales o fiestas. Todo un referente que al derogarse el Estatuto de Internacionalidad de la ciudad, cayó en franca decadencia pasando por varias etapas que culminarían 
con su cierre definitivo. Tras unas obras de emergencia para reparar parte de las cubiertas y afianzar mínimamente su estructura, colapsada en parte tras el asentamiento de la cimentación, el edificio se encuentra hoy abandonado y en avanzado estado de ruina. Un fantasma que levita entre otros edificios vacíos y solares sin uso definido, formando una especie de periferia interior donde se dan todo tipo de conflictos topográficos, urbanísticos y sociales.

Existen, no obstante, varios proyectos sociales que estuvieron encaminados a su reactivación. Con motivo del centenario de su inauguración (1913-2013) la pintora Consuelo Hernández junto con los escritores Jesús Carazo, Santiago Martín Guerrero y Mezouar El Idrissi, publicaron el libro "Un escenario en ruinas. Llamamiento artísticoliterario por la recuperación del Gran Teatro Cervantes de Tánger", cuyo título resulta suficientemente explícito. También colectivos como el llamado «Sostenerlo que se cae»-«Soutenir ce qui tombe»- más activos en redes sociales, proponían recuperar ese espacio fundamental para la vida cultural de la ciudad, y hasta la Dirección General de Vivienda y Arquitectura del Ministerio de Asuntos Exteriores propuso un proyecto de rehabilitación que fue presentado en 1994 por Velles Arquitectos. Contribuciones desde distintos ámbitos sociales, culturales y administrativos que supusieron un importante impulso gracias a la repercusión que, en mayor o menor medida, llegaron a tener en diferentes medios.

A estas iniciativas quiso sumarse el Taller de Proyectos 6 durante el curso 2014-2015, pero abordando su recuperación desde una perspectiva lo más amplia y diversa posible. Por un lado, el bien en sí mismo debería estar, como lo estuvo en su momento, perfectamente integrado en la trama urbana circundante. Una de sus más importantes patologías, además de las físicas, era la práctica quiebra de su entorno, un área marginada y olvidada por la administración y los ciudadanos que la entendían, pese a encontrarse en el corazón de la Nouvelle Ville, como marginal y peligrosa, un hecho al que hasta ese momento no se había prestado atención. Por ello, recuperar el edificio debía entenderse como parte de una operación urbana más amplia, en la que éste entrara en carga, además, por sus valores de carácter paisajístico cultural. Por otro lado, se entendía que, pese a los destrozos generales y a los peligros de estabilidad general, sobre todo en las áreas apuntaladas, el edificio era perfectamente recuperable, pues los daños, siendo graves, no eran irreversibles. Sin embargo, no se trataba de hacer una restauración mimética de lo que en su momento de esplendor fue, ni plantear para él un programa 
similar al que tuvo desde su concepción original, pues ese tipo de operaciones está, en la mayoría de los casos, abocada al fracaso. El proyecto, por tanto, debía ser capaz de poner en valor la herencia recibida, pero, en paralelo, dar la posibilidad de que en él pudieran desarrollarse propuestas innovadoras más acordes a la nueva realidad sociocultural de la ciudad. Frente a algunas reivindicaciones en sentido contrario, era necesario partir de la memoria del lugar, de su transcurrir histórico, reprogramándolo y dotándolo con las infraestructuras necesarias para dar cabida a la personalidad y reivindicaciones de la comunidad a la que iba destinada, de manera que ésta pudiera hacerlo suyo de una forma natural, contribuyendo, así, a su futuro enriquecimiento. [4] [5]

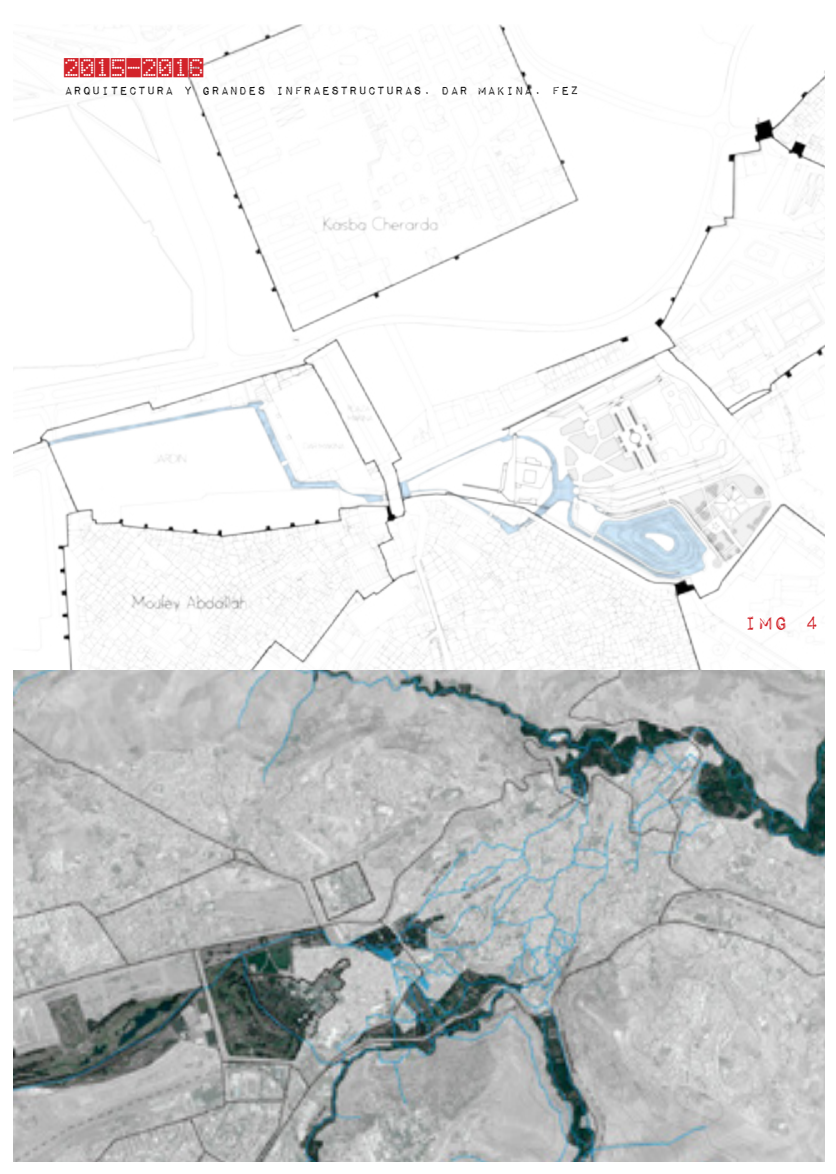

Fig.4. 015-2016 Taller de Proyectos 6. ETSA Granada. ARQUITECTURAY GRANDES INFRAESTRUCTURAS. Dar Makina. Fez. Elaboración propia a partir de: Plantas generales. Levantamiento colectivo sobre base cartográfica. Feb. 2015. Óscar García Fernández. Propuesta de intervención en el entorno de Dar Makina. Feb. 2015.
Sede de la Qarawiyyin, la universidad más antigua del mundo, la ciudad de Fez fue fundada en el siglo IX y alcanzó su apogeo bajo la dinastía de los Merinidas entre los siglos XIII y XIV, cuando reemplazó a Marrakech como capital del sultanato. El tejido urbano y los principales monumentos de su Medina -madrazas, fonduks, palacios, riads, mezquitas, fuentes, etc.datan precisamente de este periodo. A pesar del traslado de la capital en 1912 a Rabat, $\mathrm{Fez}$ sigue conservando su condición de capital cultural y espiritual del país.

Urbanísticamente, hasta la independencia de Francia, la ciudad quedaba dividida principalmente en tres áreas 
básicas: La antigua y la nueva Medina y los nuevos barrios de trazado moderno europeo a cuyo conjunto se denominó, como en otras ciudades marroquíes, la Nouvelle Ville. La antigua Medina, que conserva su espléndido conjunto habitacional y numerosos edificios monumentales, fue fundada por la dinastía Idrisí entre 789 y 808 d.C. Está compuesta principalmente por dos grandes áreas fortificadas, separadas por el Fez wadi (Oued Bou Khrareb): la orilla de los Andaluces en la margen derecha, en la que se asentaron definitivamente los musulmanes procedentes de Córdoba y otros puntos de la península, y la Qarawiyyin, fundada por Fatima y Meryam, hijas de Muhammed Ben Abdellah al Fihri, que emigradas desde la ciudad de Quirawan (Túnez) en el siglo XI, optaron por la margen izquierda. En ambas orillas se construyeron sendas mezquitas principales, la Qarawiyyin y la de los Andaluces, símbolos religiosos por excelencia de cada una de ellas, lo que influiría decididamente en que, a pesar de la unificación llevada a cabo por la dinastía de los Almorávides, al rodear el conjunto con una única muralla, persistan, todavía hoy, las diferencias espaciales, morfológicas y hasta sociales. Entre los siglos XII y XIII, ya bajo el mandato de la dinastía de los Almohades, Fez el-Bali crece de forma exponencial hasta colmatar el área de expansión prevista tras el trazado de la cerca primitiva, hasta que a partir de 1276, ya con la

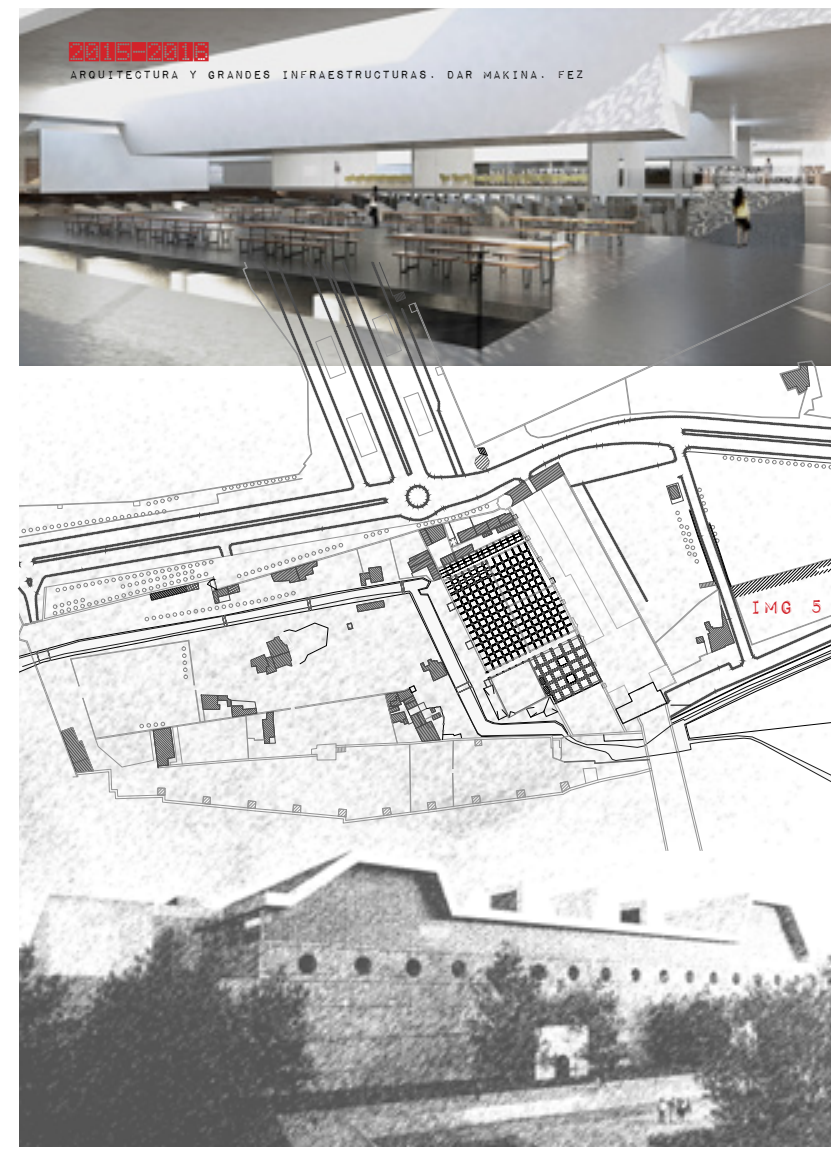

Fig.5. 2015-2016 Taller de Proyectos 6. ETSA Granada. ARQUITECTURAY GRANDES INFRAESTRUCTURAS. Dar Makina. Fez.

Elaboración propia a partir de: Planta general. Levantamiento colectivo sobre base cartográfica de la Prefecture et Commune de Fes. Arrondissement les Merinides sep. 2009. Nov. 2015. Antonio Delgado Serrano.Vista interior y exterior. Propuesta de intervención en Dar Makina. Feb. 2015. 
dinastía de los Merinidas en el poder, se funda, al sur oeste de Fez elBali, la nueva Medina de Fez el-Jdid, trazada con criterios urbanísticos más próximos a las consideraciones espaciales desarrolladas en la $\mathrm{Me}-$ dina de Marrakech. En esta nueva ciudad, quedarán ubicados, además del palacio y los jardines reales, ahora desarrollados más ampliamente, gracias a la ocupación de una considerable extensión de terreno fértil y relativamente plano, el cuartel general del ejército, así como otras fortificaciones y áreas residenciales de interés, que darían al recinto un considerable peso específico. A partir de ese momento, ambas entidades evolucionarán en paralelo hasta formar una de las más extensas e importantes metrópolis islámicas. En ese contexto, llegaría a producirse una singular simbiosis entre la gran variedad de formas arquitectónicas generadas, las cuales darían lugar a un rico paisaje urbano, que fusionado con la topografía y el paisaje natural circundante, contribuirían a la creación de un conjunto excepcional. La arquitectura en general, tanto la civil, como la religiosa o la residencial, en sus diferentes niveles y escalas, se caracterizará, entre otros valores, por las técnicas de construcción y la refinada decoración, desarrolladas a lo largo de un período de más de diez siglos, donde el conocimiento y las habilidades locales se entretejían con diversas inspiraciones e influencias exteriores, provenientes tanto de Andalucía como de Oriente y de manera transversal de los vastos territorios africanos conquistados.

La Medina de Fez es hoy, gracias a las importantes obras de renovación urbana llevadas a cabo a partir de la declaración en 1981 de Fez el-Bali como patrimonio mundial por la UNESCO, una de las ciudades mejor conservadas de este periodo, pero su mayor interés reside en que todavía hoy, se mantienen poco alteradas sus funciones y atributos originales. Es decir, no sólo posee un patrimonio arquitectónico, artístico, arqueológico o urbano excepcionales, sino que cuenta con un tejido urbano y social suficientemente enraizado que se ha mantenido durante siglos homogéneo y cohesionado. La Medina de Fez es, en ese sentido, una suerte de microcosmos perfectamente urdido, gracias a lo cual, y a pesar de los problemas de tugurización, de deterioro arquitectónico o de sobre población, es posible aún entrever un estilo de vida, unas habilidades, unos saberes y una cultura del lugar que persisten y se renuevan constantemente, a pesar de los efectos depredadores que en ese sentido afectan a las sociedades modernas en evolución y, sobre todo, de un turismo depredador que lentamente afecta a sus más íntimas estructuras.

Entre Fez el-Bali y Fez el-jdid se abren una serie de vacíos que primigeniamente debieron ser simples descampados sin uso específico o 
áreas de huertas, más o menos estructuradas y que hoy constituyen una serie de espacios encadenados de alto valor urbano y paisajístico, los cuales tienen como elemento fundamental de relación el discurrir del río Fez. El Fez Wadi, río que da nombre a la ciudad, parece como si en esta zona se fuera deshilachando en múltiples venas, formando en su transcurrir una red hidráulica que, a pesar de quedar truncada con las nuevas formas de abastecimiento generadas durante el Protectorado, permanece prácticamente inalterada y en pleno funcionamiento para el abastecimiento de jardines, fuentes, lavaderos, casas o industrias. En su momento de mayor esplendor, el Fez, convertido ya en río urbano, daba vida a los jardines de Dar Baida, a la Plaza Boujloud, al jardín de Jnan Sbil, a la Plaza de Muley Hassan, sede del Festival de Música Sacra de Fez, a la puerta de Sbaâ y Bab Dekakene, que remata la vía principal de la Medina de Fez el-Jdid y conecta por el extremos noreste del Palacio Real o a Dar Makina y sus espaciosos terrenos casi vírgenes e infrautilizados desde el abandono de la antigua fábrica de armas. Un conjunto único en el que, sin embargo y a pesar de la exhaustiva definición de cada uno de estos espacios y de la inagotable labor de revitalización, existen, todavía hoy, flecos, fisuras, discontinuidades y ruinas. Territorios de oportunidad sobre los que un arquitecto debería reflexionar, posando su mirada sobre ellos, siempre, con ojo crítico y escrutador. Es por esta razón que durante el curso 2015-2016 se trabajó en la investigación de estos ámbitos urbanos, en sus sistemas de articulación y en la formulación de arquitecturas contemporáneas, a partir de la modificación de alguna o algunas de ellas y de las relaciones del sistema al que pertenecen, en particular en la antigua fábrica de armamento de Dar Makina.

Esta línea de investigación, en general, obliga siempre a un reconocimiento previo de las relaciones que operan en el lugar de intervención y a la definición pormenorizada y ampliada del ámbito de trabajo, por lo que cada propuesta debe construir su propio campo de operaciones. Sólo a partir de la relación con los construido y de sus propios criterios de intervención, el arquitecto dispondrá de armas suficientes para poder proyectar sobre el patrimonio, sobre lo heredado, entendiéndolo como fuente de energía para el futuro y no como un lastre que entorpece la evolución social y urbana. En este sentido, es necesario considerar que no hay modelos de arquitectura a los que recurrir, ni hay estilos, ni una metodología de intervención, solo gramáticas/arquitecturas, relaciones que promueven un nuevo espacio para la naturaleza del hombre y sus circunstancias. La inercia, la lógica constructiva, la tecnología, la percepción, la escala, el uso, la razón, el mercado, o la política, serán algunos de los factores que ayuden 
a formular esa nueva gramática arquitectónica y el tipo de sutura con la naturaleza de la ciudad existente. Proyectar se convierte, de esta manera, en una forma de intervenir con responsabilidad en el futuro, de invertir en él, de imaginarlo como resultado de un equilibrio de fuerzas en las que no deben quedar fuera la ecología, la sostenibilidad, la funcionalidad y la expresión cultural del mundo que lo ejecuta.

El proyecto se desarrolló en dos fases. En la primera, desarrollada como taller internacional junto a los estudiantes de l'Ecole National

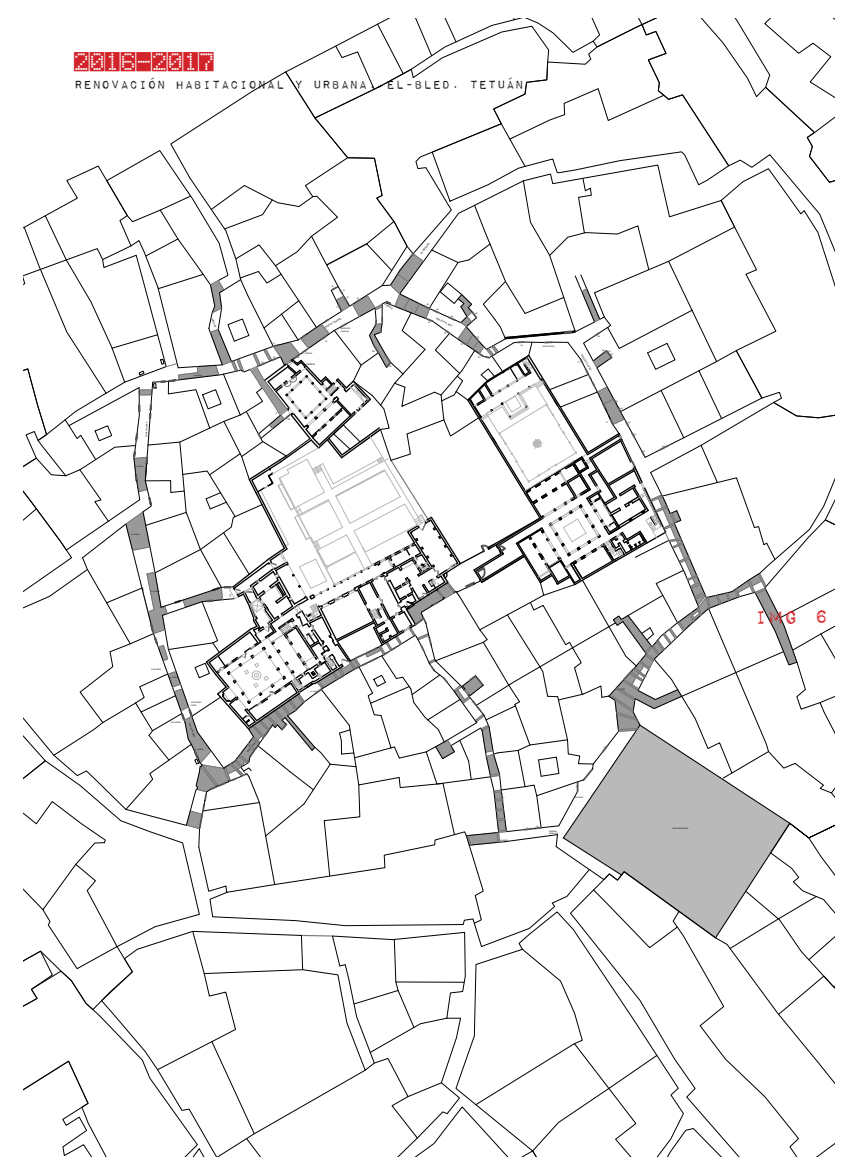

Fig.6. 2016-2017 Taller de Proyectos 6. ETSA Granada. RENOVACIÓN HABITACIONALY URBANA. El-Bled. Tetuán.

Elaboración propia a partir de: Planta general El Bled. Tetuán: Levantamiento colectivo sobre base cartográfica. Plantas Casa Erzini, Palacio Bricha y Casa García, cedidas del Proyecto de Cooperación: Iniciativa para Restauración y Rehabilitación funcional de la Medina de Tetuán, financiado por CICODE. Universidad de Granada. Nov. 2016
d'Architecture de Fez, se buscó el reconocimiento del paisaje cultural generado por el río Fez, que en ese ámbito espacial llegó a generar situaciones de una riqueza y diversidad extraordinarias. Un conjunto urbano específico que en estos momentos, debido al abandono de infraestructuras tan importantes, a la baja calidad y mala conservación de algunos edificios recientemente construidos y a que algunos espacios quedan mal conectados con el resto de la ciudad, se ve mermado en sus enormes posibilidades de desarrollo. Posteriormente, una vez asentados los criterios para su recuperación, la segunda fase del trabajo, desarrollada en el taller de proyectos de la Escuela de Arquitectura de Granada, se daría forma concreta a un proyecto de recuperación de la antigua fábrica de armamento, Dar 
Makina, para su reutilización como espacio dedicado a la cultura contemporánea que pueda ayudar a completar y revitalizar, no sólo el edificio en cuestión, sino todo el área de estudio, incluyendo la zona de expansión del edificio con sus vacíos y construcciones menores y su entorno inmediato. En ese sentido, el proyecto debía considerarse como una dotación cultural y social para la Medina, pero con vocación de dar cobertura a toda la ciudad y la región de Fez-Bulmán, cuyas aspiraciones colectivas se enfrentan hoy a nuevos discursos y nuevos retos. [6, 7 y 8]

El 27 de noviembre de 2012 se cumplieron cien años de la firma entre Francia y España del Estatuto del Protectorado Español en el Norte de Marruecos. Un año después, el Real Decreto de 27 de febrero de 1913 establecía la organización general de la ocupación y la capitalidad de Tetuán como sede del Alto Comisariado Español. A partir de ese momento, territorio $\mathrm{y}$ ciudades empiezan a ser ocupados de manera relativamente pacífica por una población de inmigrantes que comenzaban a llegar de la península en busca de nuevas oportunidades. Para ello fue necesario crear un escenario favorable, asegurar un afianzamiento legal $y$ territorial que en este caso se hizo a partir de una serie de premisas, las cuales, a la postre, constituyeron las herramientas básicas y diferenciadoras

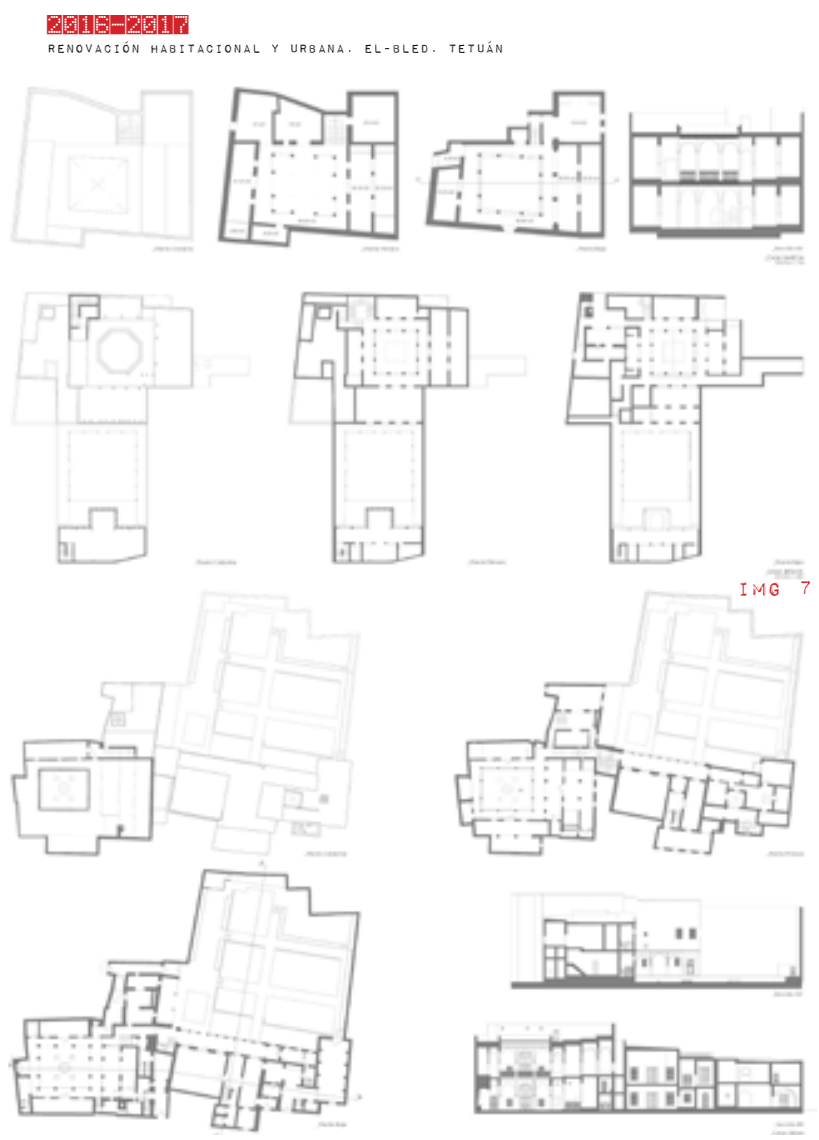

Fig.7. 2016-2017 Taller de Proyectos 6. ETSA Granada. RENOVACIÓN HABITACIONALY URBANA. El-Bled. Tetuán.

Elaboración propia a partir de: Plantas, alzados y secciones de la Casa Erzini, Palacio Bricha y Casa García, cedidas del Proyecto de Cooperación: Iniciativa para Restauración y Rehabilitación funcional de la Medina de Tetuán, financiado por CICODE. Universidad de Granada. Composición de Gerardo Peregrín. Feb. 2016 

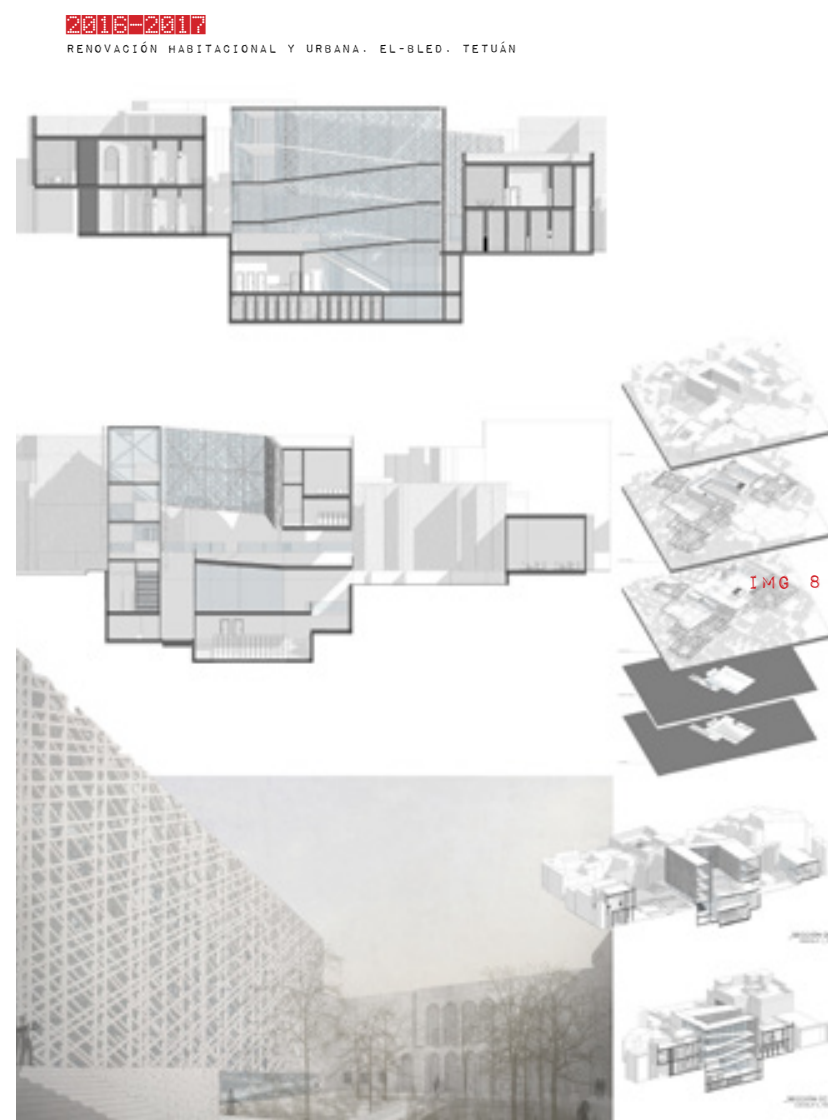

Fig. 8. 2016-2017 Taller de Proyectos 6. ETSA Granada. RENOVACIÓN HABITACIONALY URBANA. El-Bled. Tetuán.

Elaboración propia a partir de: Gerardo Peregrín. Propuesta de intervención en El Bled. Tetuán. Feb. 2016 de la acción colonizadora de España en el Norte de Marruecos. Por un lado, el reconocimiento mutuo de la diversidad social y, por tanto, cultural, que se había ido gestando a lo largo de tantos siglos de alianzas y relaciones más o menos turbulentas. Por otro, el uso de un modelo de estructuración territorial que partió de la idea de dar soporte y preferencia a los movimientos militares con el fin de asegurar su más efectiva defensa $y$, por último, "la importancia capital de la función interventora" (Rodríguez Mediano \& Felipe, 2002 , p. 249). Como en otros textos, en el trabajo de Bravo Nieto titulado la Arquitectura y el urbanismo en el Norte de Marruecos, se mantiene que esta intervención consistió en una completa reorganización del territorio consistente en afianzar una serie de puntos estratégicos -la mayoría ya existentes, primero en la costa y luego en el interior- y su conexión por nuevas vías terrestres y marítimas, remodelando o construyendo ex novo carreteras, ferrocarriles y puertos por los que desplazar a las tropas y más tarde a la población civil (Bravo Nieto, 2000).

Este modelo no era novedoso, pues compartía muchas líneas estratégicas con el que Francia impulsó en el territorio que se hallaba bajo su jurisdicción, pero en este caso se instauró con matices propios de la idiosincrasia marroquí y, cómo no, de la española del momento. En ese sentido, es importante señalar que en el contexto relacional que se formó, se darían 
dos niveles de intervención: uno territorial y otro local. Mientras que el primero supuso una sutura del territorio con distintos elementos y líneas infraestructurales, el segundo, más complejo, estuvo condicionado en todo momento por esa particular relación de proximidad intersocial. La primera incursión en el país fue, por tanto, de carácter netamente militar y diplomática. Infraestructuras y edificios se iban construyendo sobre un territorio, según una planificación diseñada por los ingenieros del ejército que actuaban de manera aislada, muchas veces compulsiva e inconexa a las órdenes de los comandantes de turno, sin un control o supervisión general. No será hasta 1927, cuando el territorio parecía definitivamente pacificado tras la Guerra de África, que todo el Protectorado, además de Ceuta y Melilla, quedarían unificados en cuatro circunscripciones militares, cediendo importantes parcelas de poder y gestión al Alto Comisariado que, a su vez, dejaba el mando sobre los ejércitos. Esta bicefalia entre la jerarquía militar y las instituciones civiles, originó una profunda dualidad que también quedó evidenciada a nivel urbano. En muchas ciudades, los primeros trazados urbanos los empiezan a dibujar los ingenieros militares obedeciendo más a razones estratégicas que a una lógica urbana coherente con el lugar o con las aspiraciones propias del momento histórico y cultural en el que se vivía, generalmente de espaldas a las últimas investigaciones que en materia urbanística se estaban produciendo en el resto de Europa. Unos trazados no siempre madurados, propios del apresuramiento y la inmediatez conceptual. Sin embargo, tras la Guerra de África, cuando el territorio parece definitivamente pacificado y comienzan a llegar las primeras oleadas de población, se hizo patente la necesidad de incorporar ingenieros y arquitectos civiles a las tareas de ordenación y construcción del territorio, lo que provocó un cambio radical en los planteamientos urbanísticos.

Grosso modo, y a pesar de lo simplificado de la aseveración, el primer modelo elegido para la práctica totalidad de las ampliaciones dentro del territorio español fue el del ensanche de herencia decimonónica, con manzanas cerradas más o menos regulares. Se trataba de un trazado que, sin embargo, se apartaba de los cánones geométricos, pues debía deformarse para incorporar otras partes vitales ya construidas, generalmente cuarteles militares y caminos preexistentes estratégicos, hasta su fusión con el contorno irregular de las medinas y sus arrabales consolidados. Tampoco su dimensionado vial fue homogéneo, pues, aunque se prestaba atención a los parámetros propios del cada vez más importante fenómeno del automóvil, por otro lado, se establecían ciertas prioridades de jerarquización espacial por las cuales se definían ejes perspécticos 
y de representatividad propios del modelo urbanístico inaugurado por Haussmann en el París de Napoleón III.

Sería posteriormente cuando, partiendo de la nueva realidad social, se abordarían nuevos planes urbanísticos para la organización de amplias y saneadas áreas de la ciudad, generalmente alejadas de las medinas históricas, aunque relativamente cercanas a los ensanches, que consistían en ampliaciones en forma de ciudad-jardín con pequeños hotelitos o chalets unifamiliares para las clases más acomodadas, pero también, dependiendo de las necesidades, la construcción de barriadas obreras -casas baratas- para la población más humilde que iba llegando de la península o que ocupaban las áreas tugurizadas de del extrarradio.

A diferencia de las colonias francesas del sur de Marruecos donde se establecía una diferenciación entre la medina histórica y las nouvelles villes, en las españolas esta dualidad no era tan clara. Los españoles emigrados de la península y los musulmanes indígenas eran capaces de convivir con cierta naturalidad, tanto en el espacio de la medina como en el ensanche, compartiendo no sólo el suelo, sino sus modos de vida y la cultura hasta lograr un rico espacio social y urbano de mestizaje que se hacía eco de una tradición y compromiso forjados durante siglos. Tetuán fue desde su fundación en el siglo XV una ciudad de acogida y abierta al mestizaje. Tras la destrucción de la fortaleza medieval de origen meriní por parte de las tropas portuguesas, y de que éstos ocuparan varias ciudades del norte de Marruecos, entre ellas Ceuta en 1415, Tetuán será un punto estratégico para la defensa militar de la zona. En 1483 comienzan a llegar los primeros refugiados árabes andaluces comandados por el granadino Sidi Al-Mandri que mandaría construir en el lugar una nueva fortaleza de carácter supuestamente provisional sobre las ruinas de la anterior, lo que les permitirá defenderse de los ataques de las tribus próximas que reivindicaban la propiedad de los territorios. Poco a poco se va consolidando su núcleo original, el barrio de El-Bled (El Pueblo), perfectamente legible hoy en la trama urbana, el cual se situaba en un punto estratégico del monte Dersa, justo enfrente del monte Gorges. Entre ambos el río Martil que regana la fértil vega de la que se abastecía toda la comarca, en cuya desembocadura, a escasos 7 kilómetros de la ciudad, se situaba el puerto que permitía una fácil salida y comunicación con el exterior. Un lugar rico y bien defendido al que más tarde llegarían los judíos sefardíes huidos de la península expulsados por los diferentes decretos de los Reyes Católicos y los refugiados moriscos que, como éstos, se vieron obligados a salir de la península, acosados durante décadas y expulsados definitivamente por la administración de Felipe II. Colmatado El-Bled, los moriscos fueron ocu- 
pando la zona noreste de la medina, fundando el barrio de Al-Ayun (Las Fuentes), lugar donde aún se conservan los nombres originales de calles y mezquitas en árabe andaluz.

Habrían de pasar cuatro siglos para que los descendientes de aquellos primitivos andaluces y españoles se encontraran de nuevo, aunque fuera debido a algo tan circunstancial y negativo como la toma de la ciudad en 1860 por las tropas de Isabel II de España. Un breve reencuentro que iría incrementándose lentamente en el tiempo hasta la proclamación del Protectorado Español en el Norte de Marruecos y la designación de Tetuán como su capital administrativa.

Esta condición de ciudad mestiza también dejó su huella en la arquitectura. En Tetuán ya desde el siglo XIX y previo a la instauración del Protectorado, se llevan a cabo intervenciones dentro de la medina alejadas de su tradición constructiva. Ejemplos como el de El Mellah -el barrio judío- proyectado ex profeso por ingenieros portugueses y ampliado posteriormente, los derribos y nuevas edificaciones de edificios estratégicos y comunitarios -correos, policía, iglesia, consulados, etc.- o las aperturas y esponjamientos en la trama interna de la ciudad para posibilitar el movimiento de tropas, transformarán la trama urbana islámica original para incorporar otras tipologías exógenas que permiten confirmar esa actitud tolerante y su vocación de mestizaje. En un plano de 1912 dibujado por el arquitecto Alfonso de Sierra Ochoa, que serviría como base para las actuaciones españolas en el ensanche, puede verse cómo en esa fecha aún no estaba colmatada la superficie interior de la Medina por lo que se deduce que, además de las ampliaciones externas del Ensanche, durante esos años de convivencia la ciudad continuó su proceso de consolidación.

Una de las mayores operaciones urbanas intramuros se produciría tras el abandono forzoso del antiguo Mellah el-Bali por decreto del sultán Muley Sliman en el s. XVIII y su traslado a la zona sur de la Medina, lo que dejaría libre un amplio sector al norte de la ciudad, que permitió la construcción de la nueva mezquita mayor y el levantamiento de varias casas nobles. El entorno delimitado por las curtidurías de Bab Mqabar, las calles Aragón, Marstan, Metamar, Slokia de Sidi Saidi y Bab Sefli, contienen un importante número de elementos arquitectónicos catalogados y en él se producen interesantes situaciones urbanas que se concentran en torno a la mezquita mayor, entra las que destacan la Zagüía de Sidi Ali Ben Raisun, las mezquitas de Bensalah, la Rabta y Ghailan, así como una profusa y rica arquitectura doméstica de origen y configuración humilde que se entrelaza con algunas de las casas-palacio más importantes de la 
ciudad, como la Aragón, la García, la Erzini o la Larbi-Bricha (Abdeluahid-Bricha), construidas por ricos comerciantes. Estas dos últimas, por su dimensión y etapa histórica de construcción, pertenecen a la tipología denominada "casa patio de doce pilares y arcos" que llegó a desarrollarse profusamente durante el siglo XVIII y que hoy son las más extendidas en la Medina, pero, en este caso, con un tipo evolucionado que incorpora ciertas transformaciones procedentes de la arquitectura doméstica de $\mathrm{Fez}$ y Marrakech que, a su vez, quedan influidas por diferentes eclecticismos europeos. El uso de nuevos materiales permitió, no sólo una mayor durabi-

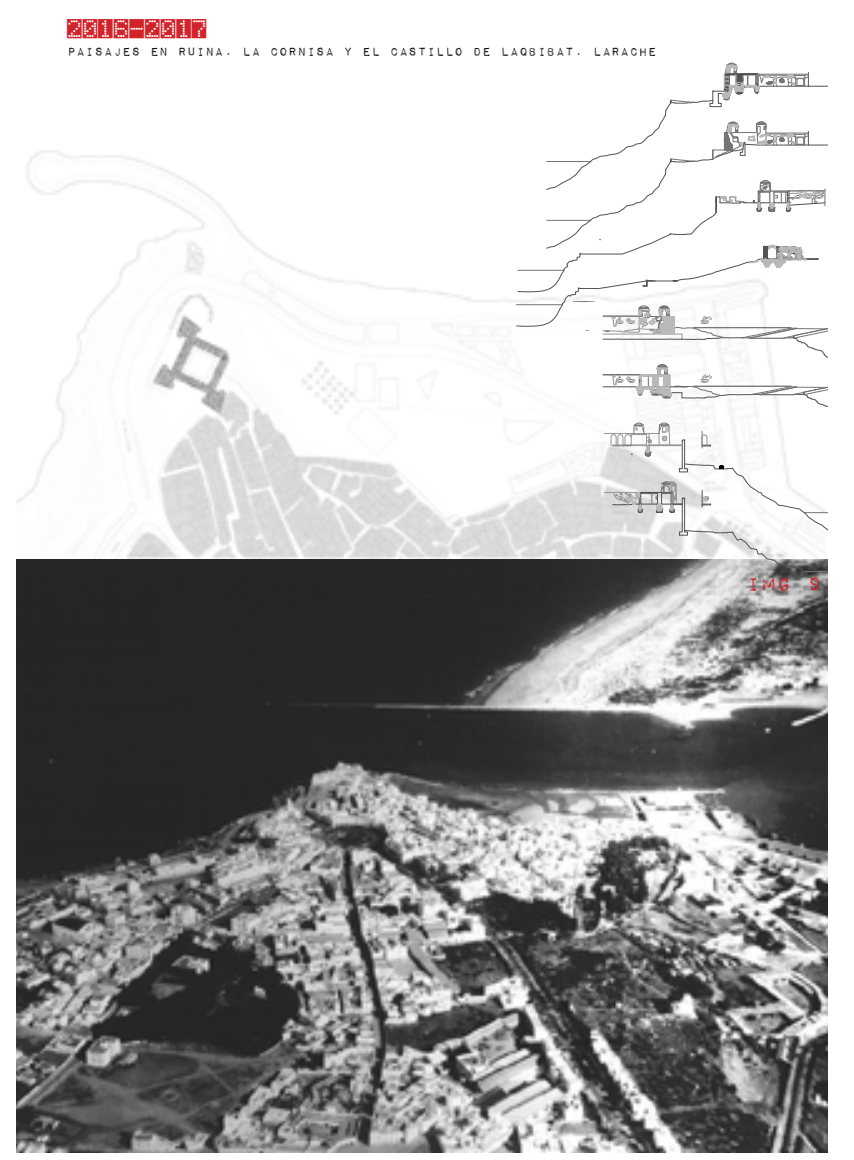

Fig.9. 2016-2017 Taller de Proyectos 7. ETSA Granada. PAISAfES EN RUINA. La cornisa y el Castillo de Laqbibat. Larache.

Elaboración propia a partir de: Planta general: Levantamiento colectivo sobre base cartográfica. Mar. 2017. Autor desconocido. Vista aérea de Larache. Recurso web: Blog Sergio Barce. 22 septiembre 2012. https:// sergiobarce.blog/2012/09/22/el-puerto-y-el-fondak-aleman-de-laracheun-relato-de-driss-sahraouil lidad, sino un desarrollo estructural más audaz, que repercutía en una mayor amplitud de espacios y precisión geométrica. La casa Larbi-Bricha tiene como particularidad, la montera octogonal del patio principal y la incorporación de un jardín trasero que junto a los dos pertenecientes a Merzini, crean un pulmón verde bastante inusual en toda la Medina.

Con estos antecedentes, el trabajo del curso 2016-2017 fue, precisamente, el entorno urbano ocupado por el antiguo Mellah el_Bali, el barrio de El-Bled, para concretar un proyecto específico de intervención patrimonial, cuyo núcleo principal lo formarían las casas LarbiBricha, García y Erzini, así como el menudo caserío circundante. Se trató, en primer lugar, de 
reconocer in situ del barrido de El-Bled en toda su complejidad espacial, detectando fases de crecimiento, valores ambientales y arquitectónicos, disfunciones, anacronismos, ruinas, posibilidades de desarrollo y cualquier aspecto relevante para un diagnóstico certero de la situación del lugar, de manera que fuera posible cimentar los criterios necesarios para abordar la recuperación de estos espacios, en distintas fases de degradación, integrándolos definitivamente y de manera natural, en la vida social y urbana de la ciudad. Un ejercicio de cuatro días de trabajo intensivo que a modo de taller internacional se desarrolló en la ciudad de Tetuán, junto a los estudiantes de l'Ecole National d'Architecture.

La segunda fase se desarrolló en el taller, dando forma a un espacio dedicado a la cultura contemporánea que ayudaría a completar y revitalizar el área de estudio. Un proyecto que debía considerarse como una importante dotación para la Medina, pero cuya vocación era la de abrirse al exterior para formar parte del sistema general de infraestructuras culturales que alimenten a toda la ciudad y la región Tetuán tan necesitada de nuevas ofertas e impulsos revitalizadores. [9 y 10]

El asentamiento de la actual Larache, tras el declive de la ciudad romana de Lixus que seguiría ocupada

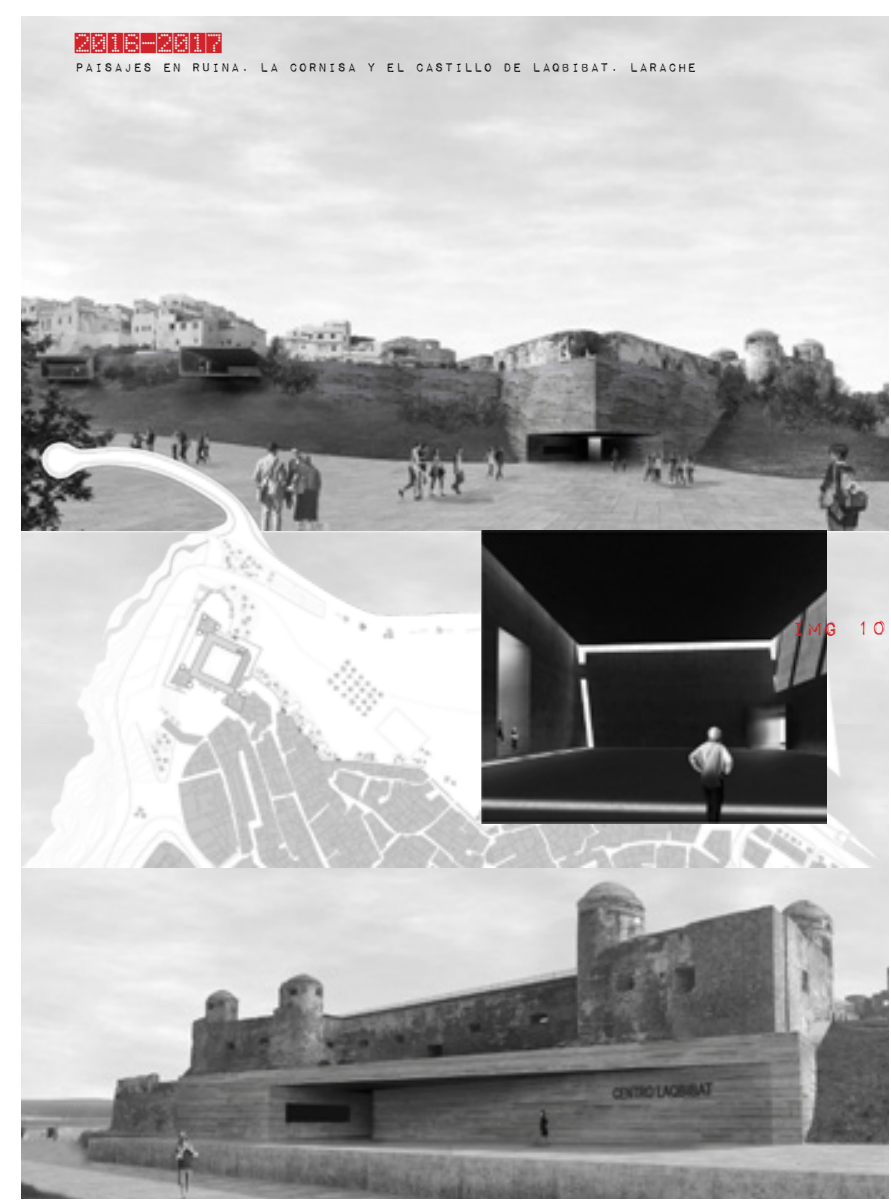

Fig. 10. 2016-2017 Taller de Proyectos 7. ETSA Granada. PAISAfES EN RUINA. La cornisa y el Castillo de Laqbibat. Larache.

Elaboración propia a partir de: Daniel García Roig. Planta general, interior y vistas exteriores. Propuesta de intervención en el entorno del Castillo de Laqbibat. Larache. Sept. 2017 
hasta la Edad Media, se hace sobre preexistencias medievales de escasa entidad, hasta adquirir cierta relevancia con las primeras expansiones comerciales y militares de españoles y portugueses que la usaban de base para sus operaciones. En el siglo XV el rey de Fez la fortifica. Aunque escasamente poblada, se trataba de una importante plaza defensiva contra los cristianos, pues su posición privilegiada la mantuvo siempre en el punto de mira de las potencias europeas. En 1610 el sultán Saadi Muhammad al-Sayj y Felipe III pactan su cesión al Reino de España, bajo cuya custodia permanecería hasta que Mulay Ismail, apoyado por las tropas francesas de Luis XIV, lograría recuperarla para el Reino Alauita en 1689. Larache pasaría desde ese momento a tener categoría de Majzén y a desarrollarse como ciudad de manera más efectiva, en la que la construcción de mezquitas, palacios o baños servirían como soporte directo al crecimiento de la población y de la medina. Sin embargo, durante esos dos siglos de relativa estabilidad, la presencia española no desapareció definitivamente de la zona. Las primeras misiones franciscanas hacen su aparición en 1768 para ir consolidando una sede definitiva en forma de hospicio con iglesia en honor de la Santísima Trinidad o la construcción en 1901 la iglesia de San Jorge. Años más tarde y como respuesta a la rebelión de las tribus contra el sultán, las tropas españolas inician en 1911 la ocupación militar de Larache desde donde toman las plazas cercanas de Alcazarquivir y Tánger. Esta situación se prolongaría hasta el 27 de noviembre de 1912, momento en el que se firma el Estatuto del Protectorado Español en el Norte de Marruecos entre Francia y España y la ciudad pasa a formar parte de los nuevos territorios colonizados. Con el Real Decreto de 27 de febrero de 1913, una vez fijada la organización general del territorio español y la capitalidad de Tetuán, en Larache se establecería la Comandancia General de la plaza y con ello una ocupación civil relativamente pacífica.

El origen de la ciudad fue, por tanto, de carácter defensivo, materializado en dos fortificaciones saadíes: el Castillo de Laqbibat -de San Antonio- y el de Laqalic -de las Cigüeñas-. Ambos fueron construidos al unísono por un ingeniero italiano cautivo del sultán que los trazó, según los modernos y efectivos criterios constructivos de la arquitectura defensiva renacentista, con baluartes apuntados en sus extremos. Con el primero, de planta cuadrada, vigilaba la desembocadura del río Lucus desde su elevado promontorio al noroeste del territorio y desde el segundo, en forma de triángulo equilátero, podía defenderse el camino de Fez al sureste.

Una vez instaladas las tropas españolas en 1610, un proyecto de Bautista Antonelli uniría las antiguas fortalezas saadíes con un lienzo 
de muralla que servía para arropar y defender la antigua Alcazaba y sus arrabales, lo que permitiría la definición de un perímetro urbano que tardaría trescientos años en colmatarse, algo que no ocurriría hasta la instauración del Protectorado, cuando la presión demográfica obligó a un desarrollo urbanístico extramuros, según un modelo de crecimiento importado que dio lugar al Ensanche español, trazado por ingenieros llegados de la península. Prácticamente demolidas las murallas originales de la Alcazaba, de las que sólo quedan restos testimoniales, los castillos, tras pasar por distintos usos a lo largo de la historia, quedan abandonados y actualmente, sobre todo el Laqbibat, en estado de ruina.

El Castillo de Laqbibat tuvo un intento de revitalización para convertirlo en hotel de cuatro estrellas, con un proyecto redactado en 2005 por el arquitecto marroquí Ahmed El Khachani. Aprobado el proyecto, licitadas e iniciadas las obras de remodelación, éstas quedaron paralizadas.

Hoy, demolidas partes originales del bien y hecho un importante desmonte del promontorio que daba frente al mar para construir escaleras y estacionamientos, sólo quedan en pie algunos muros perimetrales del edificio histórico y una estructura emergente de hormigón armado que debía dar forma al patio-vestíbulo del futuro hotel. Su estado de ruina constata un fracaso general en todos los niveles sociales y urbanísticos, pero también una oportunidad para dar paso a otras posibilidades de renovación urbana, lejos de las fórmulas habituales que, hasta ahora y en salvadas ocasiones, han tratado de borrar las huellas del pasado o de reconstruirlas de manera más o menos ajustada a las preexistencias.

El trabajo propuesto durante el segundo cuatrimestre del curso 2016-2017 incidía sobre el concepto ampliado de patrimonio donde arquitectura, arqueología, ecología, medio ambiente, ciudad y paisaje se funden para elaborar una propuesta integrada de intervención en el entorno del Castillo Laqbibat. Un ejercicio abierto a que las distintas propuestas pudieran moldear su propio plan de acción y su estrategia de intervención, de manera que las ideas surgieran sin un programa ni enunciado previos, a partir de las reflexiones e inquietudes personales de cada estudiante y de la propia experiencia del lugar. Se trataba de aprovechar los tiempos de crisis, la falta de medios económicos y financiación públicos, para repensar espacios obsoletos y su puesta en valor, en busca de soluciones alternativas al desarrollo convencional con el fin de activar la cultura en tiempos de escasez, proponiendo centros de innovación urbana con base social y participativa. Acciones y estrategias inacabadas, antes que soluciones finales de carácter edificatorio y con- 
creción formal. Serían factores a tener en cuenta, la situación propia del ámbito espacial específico, su accidentada topografía, la nueva cultura urbana que se está fraguando entre los colectivos sociales y artísticos de la ciudad, la posición estratégica del bien entre el Balcón del Atlántico al oeste y la Corniche al este, así como los restos de la batería Sidi Bouqnadel y del fuerte de Santiago, además del Boulevard que lo circunda uniendo todas las partes. Un futurible régimen de protección patrimonial para conformar un Paisaje Cultural que posibilitara su integración en la trama existente y el control del proceso de redefinición que en esos momentos se estaba gestando.

Establecida la

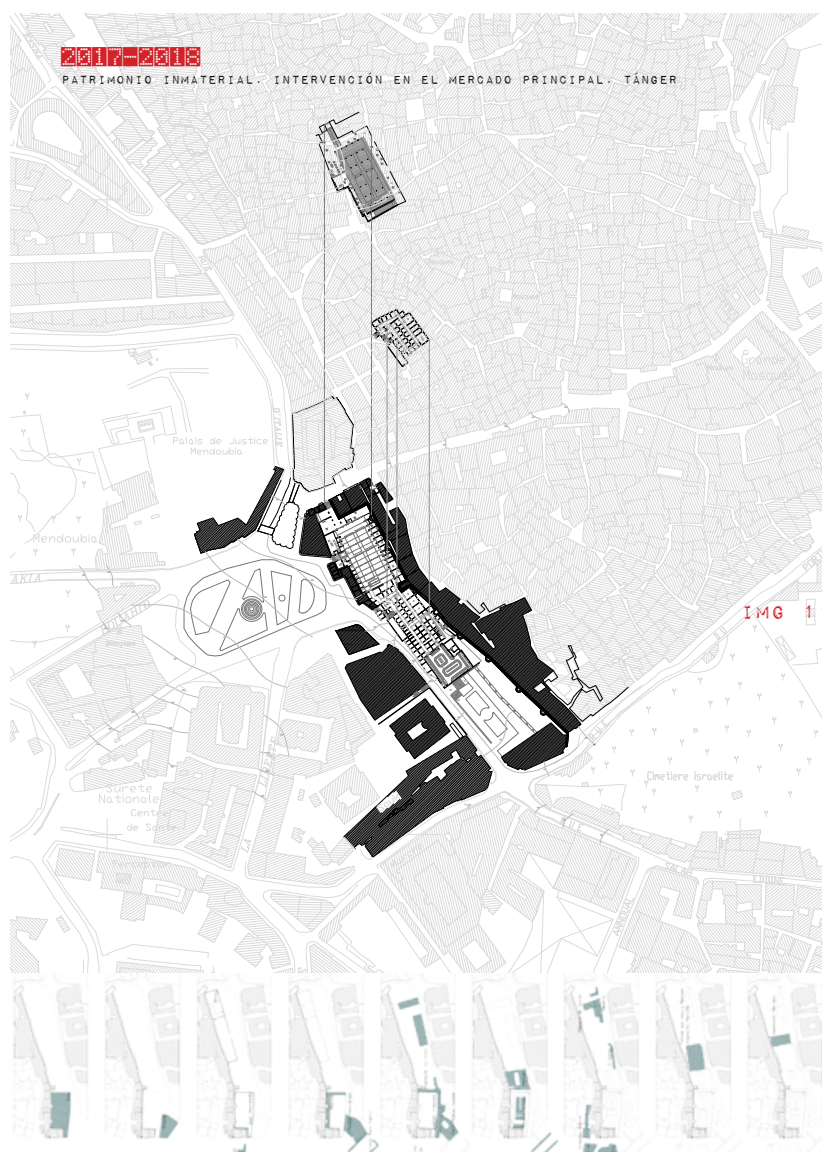

Fig. 11. 2017-2018 Taller de Proyectos 6. ETSA Granada. PATRIMONIO INMATERIAL. Intervención en el mercado principal. Tánger. Elaboración propia a partir de: Planta general: Levantamiento colectivo sobre base cartográfica. Oct. 2017. Juan Antonio Zamora Bolea y Sergio Zafra Aguado. Evolución histórica del Mercado Principal de Tánger. Ene. 2018

necesidad de entender el concepto de Paisaje Cultural como ampliación del ámbito de intervención más allá del monumento o de cualquier elemento patrimonial concreto, el trabajo contribuiría a su comprensión, preservación, difusión y puesta en valor con los medios propios de la disciplina. Para ello, debería atenderse a la definición del área de influencia de dicho Paisaje Cultural como área de protección y ambientación, así como de las relaciones y conexiones existentes con el resto de áreas culturales, ambientales o naturales próximas o lejanas (Medina, Ensanche, Balcón del Atlántico, el puerto pesquero, la playa, la Corniche o el parque de ladera). Era imprescindible, por tanto, dar forma 
a un territorio heterogéneo, englobando, además de las áreas de intervención urbana y natural, los itinerarios y senderos históricos, los aspectos inmateriales que confluyen en el lugar o las lógicas espaciales desarrolladas y mantenidas a lo largo de la historia, pues sólo de esta manera era posible presentar su lógica espacial y cultural. Se trataba, en definitiva, de realizar un proyecto de reconversión y remodelación integral en el que tendría una especial relevancia el acantilado casi destruido en la actualidad y el Castillo de Laqbibat, incluidas, si así se considera necesario, las estructuras de hormigón posteriores, para albergar, entre otros, un auditorio al aire libre para dar sede a un futuro festival de música, danza, teatro y cine. [11 y 12]

"La personificación de la conciencia cívica era la Comisión de Higiene. Aunque este consejo de oficiales consulares europeos se había establecido por primera vez en 1831, su única función, que era la de poner en cuarentena el puerto, se había quedado obsoleta desde hacía tiempo a medida que las nuevas ideas sobre salud pública apostaban por mejorar la ciudad en vez de establecer lazaretos. Un grupo de residentes europeos intentó reactivar la organización basándose en este

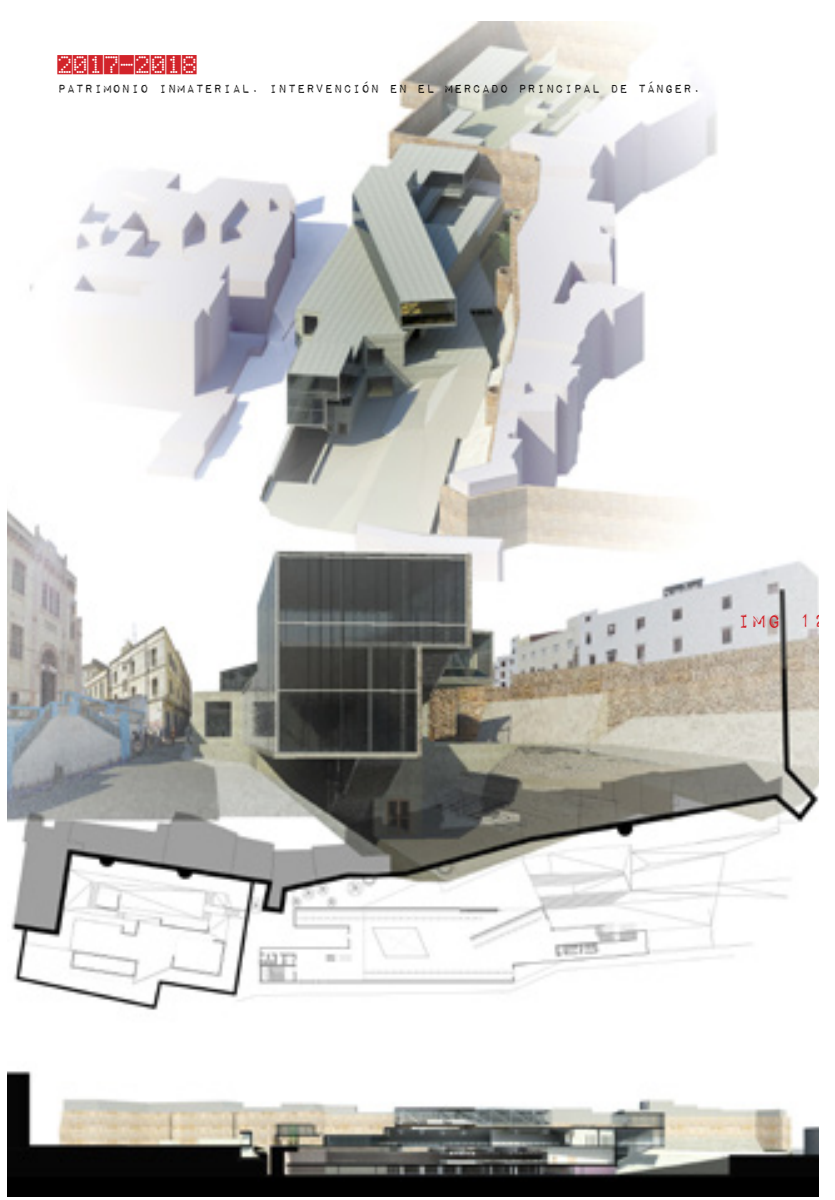

Fig. 12. 2017-2018 Taller de Proyectos 6. ETSA Granada. PATRIMONIO INMATERIAL. Intervención en el mercado principal. Tánger. Elaboración propia a partir de: Planta general Álvaro Castillo Parrilla. Propuesta de intervención en el Mercado Principal. Tánger. Ene. 2018. 
nuevo énfasis urbano de 1870 pero la Comisión de Higiene y Limpieza como se llamaba ahora, languideció por falta de ingresos y apoyo oficial. A finales de la década de 1880, la Comisión se refundó sobre cimientos mucho más sólidos, ganándose el reconocimiento de las autoridades locales y adoptando un sistema de financiación a base de suscripciones voluntarias. Además del alumbrado público, ésta trabajó para mejorar el pavimento, el alcantarillado y el establecimiento de normativas de edificación."

La Comisión de Higiene y Limpieza de Tánger tendría una influencia definitiva en el desarrollo urbano de la ciudad, construyendo alguna de sus infraestructuras básicas más importantes, algunas de las cuales permanecen aún hoy a pleno rendimiento. Una de aquellas infraestructuras, también una de las más usadas tanto por los españoles como por los nativos, fue el mercado principal de abastos de la ciudad, situado fuera de las murallas, junto a Bab Fahs, en el flanco noroeste del Zoco Grande.

Hoy denominado Place 9 Avril de 1947, el Zoco Grande es un espacio estratégico para el reconocimiento de la estructura urbana de la ciudad de Tánger, el cual ha ido transformándose paulatinamente desde su concepción inicial en forma de amplio descampado para actividades comerciales, hasta presentarse hoy en día como una plaza de tipo salón con jardín central en forma de isleta rodeada de tráfico. Un espacio acotado y bullicioso que sirve de nexo entre la Medina histórica y la Nouvelle Ville, en el que se encuentran la mezquita de Sidi Bou Abid, la Mendubía con sus jardines, diversos edificios de corte moderno entre los que cabe destacar el antiguo Cinema Rif y, como ya se ha mencionado, la puerta de Fahs por la que se accede al eje comercial peatonal de la calle de Siaghin que conduce hasta el Zoco Chico. De los diversos mercados específicos que contiene y conecta el Zoco Grande, el principal es el mercado de abastos cubierto, el cual mantiene prácticamente intacta su febril actividad comercial. El recinto ocupado por el mercado se parapeta tras una serie de edificaciones que constituyen una fachada superpuesta hacia el Zoco Grande y se pega a las murallas de la ciudad, aún aparentes en varios puntos. Funcionalmente queda dividido en tres áreas independientes y contiguas: el área de frutas y verduras que se aloja bajo una cubierta aérea compuesta por seis naves de chapa metálica de doble pendiente, el área de carnes y derivados, formalmente constituido según un sistema ortogonal de calles iluminadas por pequeños resquicios de luz natural y, finalmente, la lonja del pescado, un espacio amplio y bien ventilado de reciente construcción. A ello cabe añadir las diferentes 
tiendas anexas y el sinfín de vendedores, principalmente mujeres, que no ocupan un puesto permanente y fijo dentro del edificio. Completa el conjunto un pequeño recinto no construido en el que su sucinto ajardinamiento permite todavía ver un importante tramo del lienzo original de la antigua muralla, la cual conecta con las tapias del cementerio judío y la Avenida Mohamed VI al final de la Rue de la Plage.

El trabajo de curso consistiría, pues, la intervención sobre el mercado principal y su entorno próximo, es decir, el Zoco Grande, la zona ajardinada, así como su relación con las murallas que lo delimitan. Un conjunto urbano y cuyos valores patrimoniales no residen tanto en la calidad arquitectónica de los edificios que lo componen, muchos de ellos de dudoso interés, sino en su innegable valor como bien de interés etnológico. La intervención, por tanto, deberá atender a esos valores inmateriales, que van desde la disposición espacial de los puestos hasta la carga simbólica y cultural que lleva aparejado el acto mismo del intercambio de mercancías, elementos fundamentales para establecer y dar forma a un espacio dedicado al comercio tradicional con perspectivas de contemporaneidad que ayude a completar y revitalizar el área en cuestión. [13 y 14]

Marrakech es, junto a Fez, Mekinez y Rabat, una de las cuatro ciudades imperiales de Marruecos. Situada en

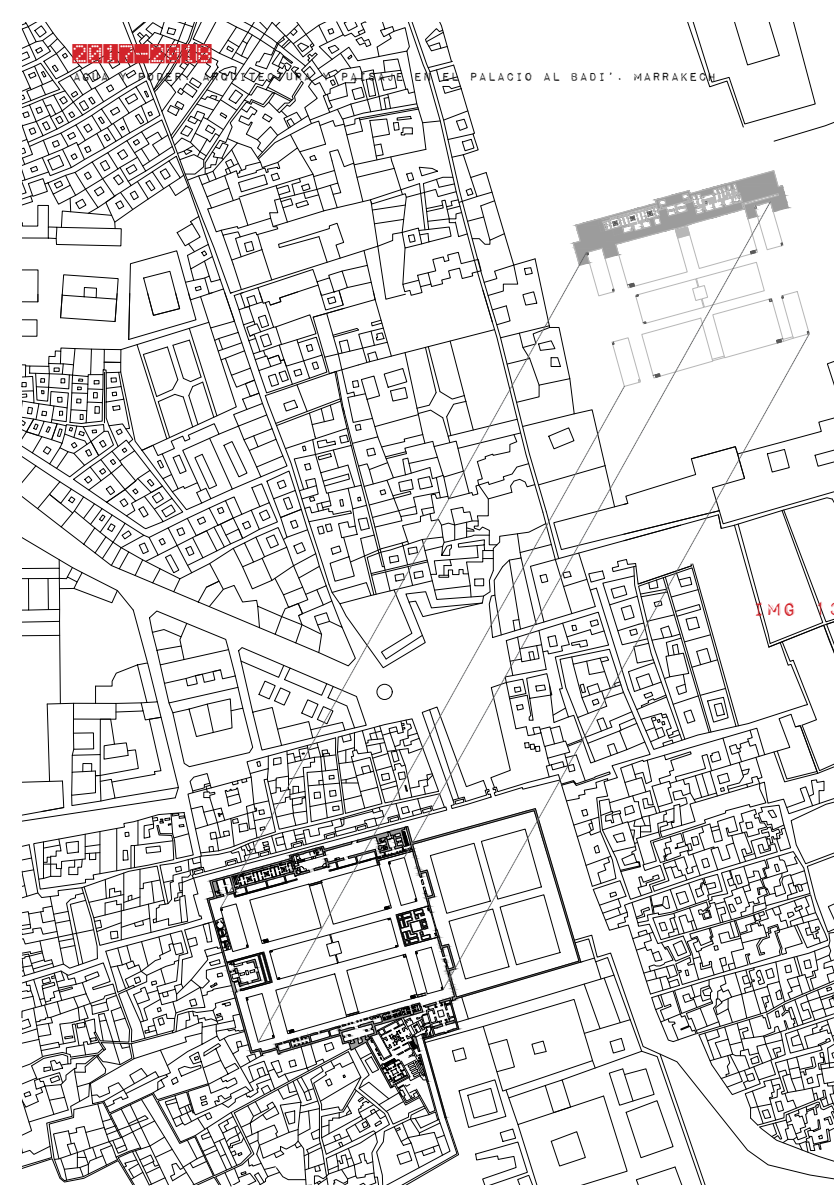

Fig. 13. 2017-2018 Taller de Proyectos 7. ETSA Granada. AGUA Y PODER. Arquitectura y paisaje en el Palacio al Badi'. Marrakech. Elaboración propia a partir de: Planta general: Levantamiento de fuan Antonio Zamora Bolea, Sergio Zafra Aguado y Yolanda Borrego Palenzuela, sobre base cartográfica. Feb. 2018. 


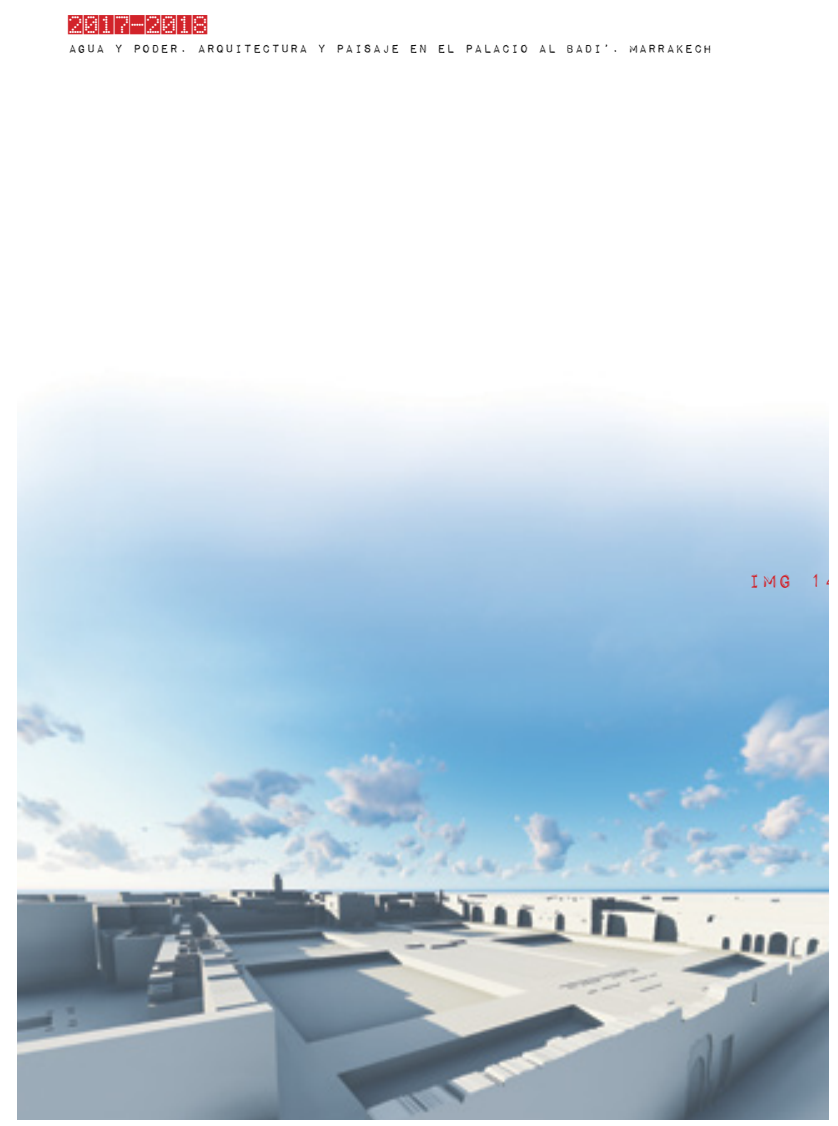

Fig. 14. 2017-2018 Taller de Proyectos 7. ETSA Granada. AGUAY PODER. Arquitectura y paisaje en el Palacio al Badi'. Marrakech.

Elaboración propia a partir de: Juan Antonio Zamora Bolea, Sergio Zafra Aguado y Yolanda Borrego Palenzuela. Levantamiento 3D. Abr. 2018 la llanura fértil del $\mathrm{Ha}$ ouz, al norte de la cordillera del Alto Atlas, está alimentada fundamentalmente por dos importantes cauces de agua: el Oued Tensift y su afluente el Oued Nfis. El Tensift, tras su descenso desde las cumbres del Alto Atlas discurre de este a oeste hasta su desembocadura en el océano Atlántico, delimitando en su recorrido la zona norte de la ciudad, mientras que el Nfis cierra por el oeste el rico espacio fértil de la vega, de la cual ésta se nutre de productos hortícolas. Además de estos dos ríos principales, la ciudad cuenta con un pequeño riachuelo, el Oued Issil, hoy con graves problemas de desecación y contaminación, que discurre tras los lienzos de la muralla del este, pues

a él se vierten los residuos de las tenerías, y la acequia de Tossoultant, que dividida en diferentes ramificaciones, fue hasta la instauración del Protectorado francés a principios de la década de los veinte del siglo pasado, el principal abastecimiento de agua potable tanto para los jardines de la ciudad, sobre todo los del Agdal, como para la población residente de la medina, a los cuales llegaba mediante una red de fuentes públicas situadas en las puertas principales y en diferentes puntos estratégicos de los barrios.

La ciudad fue fundada en el año 1070 por Yusuf Ibn Tashfin, 
el primero de los reyes de la dinastía almorávide, que la eligió como la capital desde la que gobernar todo el imperio occidental incluida la región de Al Andalus en el continente europeo. Marrakech nace en la confluencia de la ruta de las caravanas que cruzaban el territorio de este a oeste, desde la región de Tafilalet por el valle del Dades y de norte a sur atravesando el Alto Atlas y el valle del Draa. Era ésta una parada obligada para caravanas y comerciantes siempre dispuestos al trueque o al negocio inmediato. Yusif fue el primero en dar a ese primer e incipiente campamento la estructura social, política y fundamentalmente urbanística de lo que sería la ciudad de Marrakech. Tras su muerte en 1106, gobernará su hijo Alí Ben Yusuf el cual mandará a construir años más tarde la Mezquita de Ben Yusuf, el primer cinturón de murallas que delimitaría aquella todavía incipiente urbe e implantaría un sistema de irrigación muy similar al que se venía desarrollando en Persia, basado en una serie de canales subterráneos o galerías drenantes llamados kettaras o jattaras, con pozos y fuentes para el abastecimiento de agua a huertas y residencias. Un sistema que permitió, además de embellecer la ciudad, desarrollar el vasto palmeral que creció al noreste de la ciudad.

En 1147, un año más tarde de la caída de Fez y casi un siglo después de su fundación, la ciudad se rinde tras nueve meses de asedio, ante un ejército liderado por Abd al-Mùmin Ibn 'Ali, el líder de la dinastía de los almohades. Ejecutados todos los miembros de la familia real almorávide y prácticamente arrasada la ciudad, Mu'min potencia decididamente una cultura de carácter marcadamente hispano musulmán que se extenderá tanto por el Magreb como al sur de la península ibérica, llevando a cabo en ese periodo obras tan significativas como La Torre del Oro o la Giralda de Sevilla, La Torre Hassan en Rabat o la mezquita de la Kutubía en el propio Marrakech, cuyo alminar continúa siendo uno de los hitos arquitectónico-simbólico más significativos de la ciudad. No quedan atrás los proyectos hidráulicos, fundamentales para el desarrollo de la explotación agrícola de la denominada buhayra de la Menara, un término con el que se designaba primigeniamente a la gran balsa de agua que servía para el regadío de las amplias extensiones de cultivos, y que posteriormente se extendería a toda la finca regada.

Su hijo Abu Ya'qub Yusuf le sucedería a partir de 1163. Como gobernante continuó con la labor de ennoblecimiento de la ciudad y también con la construcción de una nueva buhayra a la que se denominó como El Agdal, en este caso de enormes proporciones y entendida ahora, además, como jardín y residencia real. Las buhayras 
se convirtieron entonces en proyectos paisajísticos excepcionalmente interesantes, pues aunaban en cada finca, las labores de explotación agrícola en el que se cultivaban miles de árboles perfectamente ordenados para ayudar a su mantenimiento, fundamentalmente cítricos u olivos, la inmensa alberca que acumulaba miles de hectómetros cúbicos de agua apta para regarlos, y un área residencial de carácter palaciego. Un modelo de jardín-explotación que tenía al agua, su control y sus formas, como motivo principal y casi exclusivo.

En 1184 le sucede su hijo Yacoub el Mansur bajo cuyo mandato se hizo posible la construcción de la mezquita de la Kasbah y la ampliación la ciudad en casi 10 hectáreas más, debiendo demoler para ello las antiguas murallas y creando un nuevo cinturón en el que se abriría la puerta de Bab Agnou.

Tras varios reinados poco efectivos para la dinastía almohade y para el desarrollo urbano en general, la ciudad cae en franca decadencia, un hecho que es aprovechado por el sultán meriní Abou Yussif Yacoub para tomarla en 1269. Este hecho, sin embargo, no supuso una mejora en sus condiciones de habitabilidad, pues la decisión de establecer la capitalidad del imperio en Fez, conquistada en 1248, hizo que una parte no menor de sus artesanos, intelectuales y comerciantes se trasladaran al nuevo foco de desarrollo social y cultural que viviría desde entonces una etapa de esplendor que duraría hasta la muerte del último sultán meriní en 1465, tres décadas antes de la caída definitiva del reino de Granada en 1492.

Marrakech, prácticamente abandonada, quedaría sumida durante cientos de años en un importante estado de depresión, hasta que los saadíes tomaron las riendas del imperio y de la ciudad. Mullay Abdallah crearía un nuevo espacio amurallado de 18 hectáreas para concentrar a la población judía y construiría la mezquita de Mouassine con su fuente monumental anexa. Ahmad al-Mansur, su sucesor y único superviviente de la Batalla de los Tres Reyes, logró en los 25 años que duró su reinado, devolver a la ciudad su antiguo esplendor, invirtiendo en Marrakech parte de las riquezas provenientes de los nuevos territorios conquistados para el imperio que se extendían en ese momento desde Egipto hasta Sudan, incluyendo la anexión en 1591 de la culta y rica ciudad de Tombuctú en Mali. Además de la nueva Kasbah, en esa época se construirán algunos de sus edificios más importantes, entre los que cabría reseñar la madraza de Ben-Yussef, la mezquita de Bab Boukala, el mausoleo para las las tumbas de los saadíes o rauda real, la Masarra (el palacio de Dar al Hanna), la Mushtaha (un jardín interior 
de la Kasbah) y el grandioso palacio Al Badi', iniciado en 1578 y terminado en 1593, que tomaría prestadas algunas de las características formales de las buhayras, pero ahora prácticamente desvinculado de las labores de explotación agrícola, para construir un espacio de representatividad.

A su muerte en 1603 sin nombrar heredero, el imperio comienza a desmembrarse hasta la desaparición definitiva de la dinastía en 1668, momento en el que el Moulay Rachid, el primer sultán de la dinastía alauita ejecuta a Karim el Hajj, el último de sus herederos.

A pesar de no residir de continuo en la ciudad, los alauitas, dinastía actualmente reinante en Marruecos, ampliaron sustancialmente y durante décadas el patrimonio edilicio de la ciudad con bellos y lujosos ejemplos arquitectónicos como el palacio Bahía o Dar Si Saod, ambos edificados en épocas relativamente recientes.

“El palacio al-Badi' fue un edificio de corta vida, nacido por voluntad de un soberano para satisfacer sus ansias de protagonismo y sus pretensiones políticas y que sucumbió apenas cien años después para satisfacer similares intereses materializados en otro lugar y sobre los que su predecesor arrojaba una sombra insoportable. Sometido a un expolio implacable que hizo desaparecer todo atisbo de su esplendor original, sólo quedaron sus muros desnudos y descarnados que sin embargo, a través de sus cicatrices, nos hablan de los materiales que los adornaron y las estructuras con que se cubrieron, permitiéndonos de ese modo imaginar, si no en sus detalles, si en su impacto visual, el efecto que produciría la percepción de los espacios arquitectónicos que conformaron este singular palacio". (Almagro, 2013)

El palacio al-Badi', construido como un monumento conmemorativo para celebrar la victoria del sultán Ahmad al-Mansur en la batalla de los Tres Reyes, fue uno de los más importantes espacios aúlicos de la arquitectura islámica occidental. Anexo a las estancias privadas del Palacio Real, al noreste de la Alcazaba nueva, el conjunto debía ser un símbolo inequívoco de poder: un espacio para la representatividad, las recepciones públicas y las celebraciones religiosas o civiles de carácter solemne. En él se expresaría, tanto a súbditos como a aliados extranjeros, el esplendor de una corte refinada y de un imperio rico, poderoso y pujante que había logrado conquistar vastos territorios y convertir a sus habitantes en siervos del único dios verdadero. Su importancia no sólo residía en sus poco corrientes pro- 
porciones, sino también en su situación como punto estratégico entre la medina y las sucesivas ampliaciones palaciegas, en sus refinadas soluciones espaciales, constructivas y ornamentales, las cuales aún pueden intuirse y, sobre todo, por el uso del agua en sus diferentes escalas y formas para convertirla tanto en elemento poético de disfrute y placer sensoriales, como en expresión de pujanza, solvencia y poder. Un agua que se tomaría una vez había atravesado la propia Massarra, aquí sin otra misión que seducir, ornamentar y testar un estatus de poder.

En la actualidad, tras décadas de saqueos para construir con sus materiales otras áreas palatinas del imperio, y a pesar de las reciente y poco científicas obras de restauración, el espacio está dedicado casi en su totalidad a las visitas turísticas, salvo excepciones puntuales. Su estado de ruina, lejos de ser un aspecto negativo o una rémora, ha logrado sobrevivir estructural y espacialmente y transformarse en un elemento vivo que permite nuevas oportunidades de desarrollo, como lo constata el hecho de que actualmente sea la sede anual del llamado Festival de la Risa o de manifestaciones culturales, entre ellas, las de la Bienal de Arte contemporáneo de Marrakech.

El palacio de Al Badi', a pesar de su clausura e independencia, formaba parte del conjunto palaciego del Agdal, existiendo entre ambos una conexión espacial y programática efectiva. Una relación que se extiende a la Medina, a la Alcazaba y al Mellah o antiguo barrio judío. Un espacio cerrado que, además, estaba íntimamente relacionado a otro que se abría tras los muros del este, el cual, a diferencia del gran área palatina de representación, debió ser un jardín privado de carácter menos formal y más propenso al abandono y la relajación de costumbres. Ese antiguo jardín, probablemente de carácter hortícola, cuyas trazas se intuyen en diversos grabados y planos antiguos, es hoy un espacio residual ocupado por diversas construcciones de carácter menor y corrales de desechos. Un espacio de oportunidad donde es posible recuperar parte de sus valores perdidos y hacer de charnela entre las diferentes partes de la ciudad antes mencionadas.

Una oportunidad que podría aprovecharse para hacer del palacio la sede permanente muchos de los acontecimientos sociales y culturales que actualmente se celebran en otras partes de la ciudad, como por ejemplo el Festival de Cine de Marrakech, manifestación cultural de enorme interés para la población, el cual se viene celebrando ininterrumpidamente en el mes de diciembre desde su creación por iniciativa real en 2001. Actualmente el evento tiene como sedes operativas prin- 
cipales el Palacio de Congresos y el Cinéma Colisée, además de las populares y multitudinarias proyecciones que tienen lugar en la gran explanada de la Plaza de Jmaa El Fnaa. Esta idea, sin embargo, que no debe considerarse como un fin en sí mismo, sino una excusa de intervención para la recuperación y puesta en valor de los múltiples espacios y relaciones que allí se dan, desarrollando un proyecto en el que el palacio quede perfectamente integrado. Deberán entrar carga, pues, tanto los aspectos materiales como los inmateriales que construyen la identidad del lugar, entre los cuales cabría mencionar la nueva cultura urbana que se impone a pasos agigantados entre los colectivos sociales y artísticos de la ciudad, la posición estratégica del bien o su relación con elementos esenciales de la ciudad como la cercana plaza de Jmaa el Fnaa, la Medina, la Alcazaba, las Tumbas de los Saadíes o el palacio Real del Agdal, sometidos individualmente a diferentes regímenes de protección patrimonial o medioambiental, pero conformando entre todos un Paisaje Cultural de alto valor social que es posible construir a partir de un controlado proceso redefinición espacial y formal del ámbito de protección.

El trabajo propuesto para el segundo cuatrimestre del curso 2017-2018, pretendía incidir, por tanto, sobre ese concepto ampliado de patrimonio donde arquitectura, arqueología, ecología, medio ambiente, ciudad y paisaje deben fundirse para elaborar una propuesta integrada de intervención en la que el Palacio al Badi' de Marrakech sea una pieza más, pero cuyo valor reside en que en él el trinomio agua, espacio y poder llegaron a alcanzar su máximo esplendor y representatividad. Para ello, se planteará un proyecto de reconversión y remodelación del recinto del palacio Al Badi'en general, pero con especial incidencia en el antiguo jardín trasero de manera que, fieles a su trazado histórico, pueda albergar, en la medida de lo posible, infraestructuras y dotaciones que ayuden a su reutilización, más allá de las visitas turísticas. Para ello se proyectarán, entre otros, un auditorio al aire libre con partes fijas y desmontables que pueda servir para diferentes eventos culturales, salas de recepción y exposiciones al aire libre y a cubierto, oficina de información turística y de eventos, despachos de dirección, secretaría, sala de reuniones, almacén, aseos de personal y aseos para el público, almacén general y salas de instalaciones. 


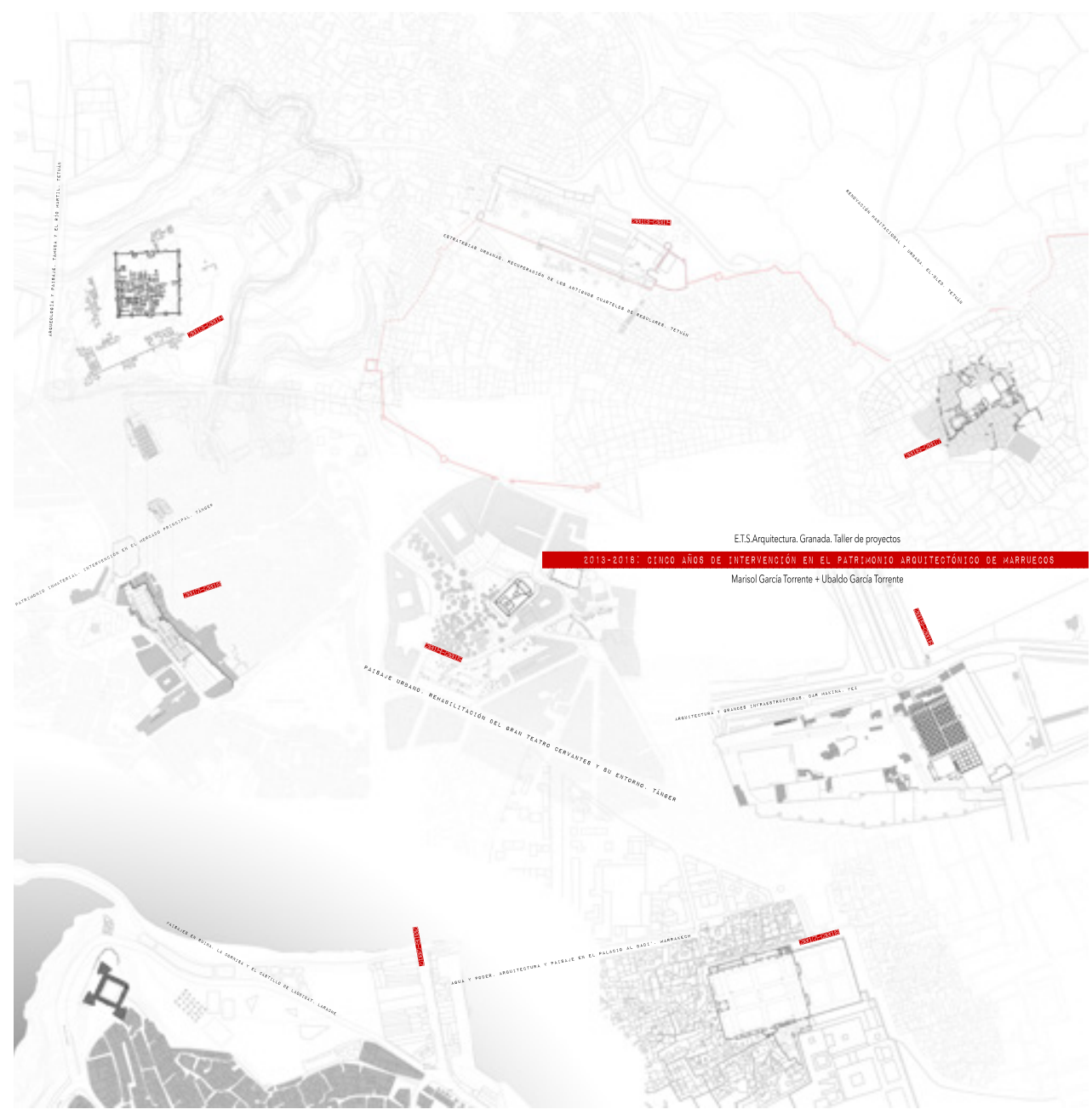

Bibliografía

ALMAGRO, A. (2013). Análisis arqueológico del pabellón occidental del palacio al-Badi' de Marrakech. (CSIC, Ed.) Arqueología de la Arquitectura (10).

BONNEMAISON, J., 1981. "Voyage autour du territoire". L"Sapce Geographique, Issue 4, pp. 249-262.

BRAVO NIETO, A. (2000). Arquitectura y urbanismo español en el norte de Marruecos. Consejería de Obras Públicas y Transportes, Dirección General de Arquitectura y Vivienda.

CEMBRERO, I. (18 de agosto de 2013). Viaje al olvido. Cervantes 
muere en Tánger. Recuperado el 30 de agosto de 2014, de El País: https:// elpais.com/cultura/2013/08/15/actualidad/1376567035_268221.html

GIMÉNEZ, G., 2000. "Territorio, cultura e identidades. La región sociocultural". En: Globalización y regiones en Mexico. Mexico: UNAM, pp. 19-53.

GIMÉNEZ, G., 2007. Estudios sobre la cultura y las identidaes sociales. México: Consejo Nacional para la Cultura. Instituto Coahuilense de Cultura. sidad.org/.

MORIN, E., 1991. Método IV. s.1.:http://www.edgarmorinmultiver-

OJEDA, J. F., 2006. "Paisaje y orden territorial en la montaña media mediterránea”. En: M. y. Torroja, ed. El paisaje y la gestión del territorio. Barcelona: Diputación de Barcelona, pp. 181-187.

PARRA, F., 2006. "La cultura del territorio. La naturaleza contra el campo". En: Islas y Cultura del Territorio. Lanzarote: Fundación Cesar Manrique, pp. 1-33.

PROTT, L (2001) "Definición del concepto de patrimonio "intangible": retos y perspectivas". En Informe Mundial sobre La Cultura 20002001. Diversidad cultural, conflicto y pluralismo”, Madrid

RAFFESTIN, C., 1980. Pour une géografie du pouvoir. París: LITEC

RODRÍGUEZ MEDIANO, F., \& Felipe, H. d. (2002). El protectorado español en Marruecos: gestión colonial e identidades. Madrid: Centro de comunicaciones CSIC. 